Review article

\title{
Propolis: The future therapy against Helicobacter pylori-mediated gastrointestinal diseases
}

\author{
Ummay Mahfuza Shapla ${ }^{a}$, Md. Jinat Raihan ${ }^{\mathrm{a}}$, Md. Asiful Islam ${ }^{\mathrm{b}}$, Fahmida Alam ${ }^{\mathrm{b}}$, \\ Md. Solayman ${ }^{\mathrm{a}, \mathrm{c}}$, Siew Hua Gan ${ }^{\mathrm{b}}$, Md. Sakib Hossen ${ }^{\mathrm{a}, \mathrm{c}}$, Md. Ibrahim Khalila, ${ }^{\mathrm{a}, *, *}$ \\ a Jahangirnagar University, Department of Biochemistry and Molecular Biology, Laboratory of Preventive and Integrative Biomedicine, Savar, Dhaka, \\ Bangladesh \\ ${ }^{b}$ Universiti Sains Malaysia, School of Medical Sciences, Human Genome Centre, Kubang Kerian, Kelantan, Malaysia \\ ${ }^{\mathrm{c}}$ Primeasia University, Department of Biochemistry, Banani, Dhaka, Bangladesh
}

\section{A R T I C L E IN F O}

\section{Article history:}

Received 3 November 2016

Received in revised form 10 August 2017

Accepted 16 October 2017

Available online $\mathrm{xxx}$

\section{Keywords:}

H. pylori

Propolis

Natural products

Gastrointestinal diseases

Microbial infections

\section{A B S T R A C T}

Helicobacter pylori (H. pylori), which is found in the stomach of approximately $50 \%$ of humans, remains there for almost the entire lifetime of the infected individual, leading to various gastrointestinal tractassociated disorders following full-blown infection. Due to the emergence of antibiotic resistance, recurrence and high cost of therapy, most antibiotic-based treatment strategies are not very effective in eradicating $H$. pylori infections. The quest for an alternative treatment free of these inconveniences is currently in demand. One of the important alternatives is propolis, produced by the honeybee Apis mellifera, which has been used to treat different diseases since it possesses a wide range of biochemical properties. Propolis has been reported as a useful therapeutic regimen against $H$. pylori, which is an important cause of gastric inflammation, peptic ulcer, gastric cancer, and lymphomas of mucosaassociated lymphoid tissues. Apart from propolis, various active compounds of other natural products have also been confirmed to be effective. This review compiles the scientific evidence of the role of propolis and other natural products against $H$. pylori-associated gastrointestinal tract-related health complexities by acing as an anti-angiogenic, anti-inflammatory, and antioxidant factor as well as via modulation of enzymatic activities.

(C) 2017 Faculty of Health and Social Sciences, University of South Bohemia in Ceske Budejovice. Published by Elsevier Sp. z o.o. All rights reserved.

\section{Introduction}

Approximately $50 \%$ of the world population is infected by Helicobacter pylori (H. pylori), a microaerophilic bacterium (Higashi et al., 2002). It was the first bacterium classified as a group I carcinogen in the report of the International Agency for Research on Cancer (IARC, 1994) based on epidemiologic evidence (Correa and Houghton, 2007; Covacci et al., 1999; Møller et al., 1995; Westblom et al., 1999). H. pylori is a unique bacterium because of its ability to colonize the human stomach, where it develops a longterm parasitic relationship (Blaser and Atherton, 2004). Apart from the presence of various virulent factors, its survival mechanisms are the modification of host immune systems such as persistent signalling by IL (interleukin-1 $\beta$ ), IL-8, and other cytokines to

\footnotetext{
* Corresponding author at: Jahangirnagar University, Department of Biochemistry and Molecular Biology, Laboratory of Preventive and Integrative Biomedicine, Savar, Dhaka 1342, Bangladesh.

E-mail address: drmikhalil@gmail.com (M. I. Khalil).
}

epithelial cells, as well as infiltration of macrophages, neutrophils and lymphocytes, acid homeostasis by acid-producing parietal cells and somatostatin-producing delta cells (Beales and Calam, 1998; Mekori and Metcalfe, 2000; Peek et al., 1995; Supajatura et al., 2002). It has also high mutation and recombination rates as well as compatibility to DNA uptake from other strains (Falush et al., 2001; Suerbaum et al., 1998). Due to its ability to cause a chronic immune response and cellular proliferative-apoptotic homeostasis, $H$. pylori causes a variety of diseases. The prevalence of $H$. pylori infection ranges from $11 \%$ in Sweden to $83.4 \%$ in China (Thung et al., 2016). Acute infection caused by $H$. pylori has been rarely diagnosed. The individuals in which $H$. pylori persistently colonize, develop different types of chronic gastritis, such as antral predominant gastritis, non-atrophic pangastritis and corpus predominant atrophic gastritis/multifocal atrophic gastritis, and $90 \%$ of cases are asymptomatic. Chronic infection may lead to gastric ulceration $(0.05 \%)$, duodenal ulceration $(0.3 \%)$, intestinal metaplasia $(0.2 \%)$, gastric cancer $(0.01 \%)$, and mucosa-associated lymphoid tissue (MALT) lymphoma (Blaser and Atherton, 2004; 
Conteduca et al., 2013; Correa and Houghton, 2007). H. pylori infections occur worldwide and studies have shown that low socioeconomic status is associated with high risk. To overcome $H$. pylori infection, several treatment strategies, including the use of antibiotics and anti-secretory agents like proton pump inhibitors, triple, quadruple, bismuth-based triple, and ranitidine bismuth citrate combination therapy, have failed to completely eradicate $H$. pylori infection, with a mean eradication rate of $65-92 \%$ due to the antimicrobial resistance of the bacteria. In addition, the use of these therapeutic methods has undesirable side effects (Beek and De Craen, 1999; Duck et al., 2004). Therefore, an effective treatment regimen for $H$. Pylori is a major clinical concern. Recently, there has been considerable interest in the use of non-antibiotic agents, such as natural products, that are effective and free from side effects.

Natural products have been traditionally used for centuries in the treatment of a wide range of ailments, including gastrointestinal disorders such as dyspepsia, gastritis and peptic ulcer (Borrelli and Izzo, 2000; Thompson Coon and Ernst, 2002). Important constituents, such as different types of polyphenols, phenolic esters, steroid glycosides, and organosulfur compounds, of natural products have the ability to combat $H$. pylori-associated diseases. A unique natural product named propolis (a resinous hive product collected by honey bees from living plants) contains different chemical compounds. Among these compounds are caffeic acid phenethyl ester (CAPE), artepillin C, quercetin, hesperidin, galangin, kaempferide, aromadendrine 4-methyl-ester, 3-prenylp coumaric acid, methyl caffeate, phenylethyl caffeate and phenylethyl dimethyl caffeate. These compounds have antibacterial, antifungal, antiviral (Kujumgiev et al., 1999), anti-protozoan (Higashi and De Castro, 1994), and antioxidant (Kanbur et al., 2009) activities. Several studies have also shown that propolis has antiinflammatory (Borrelli et al., 2002) and anti-tumour (Oršolić and Bašić, 2003) effects. In an in vitro study by Banskota et al. (2001) and Boyanova et al. (2003, 2005), it was revealed that propolis had many promising activities against various $H$. pylori strains. In addition to propolis, the common natural products with potent anti-H. pylori effects include garlic, ginger, turmeric, citrus fruits, bael, apple, cranberry, broccoli, green tea, celery, potato, virgin olive oil, liquorice, black pepper, sea almond, walnut, pear and many others. They exert their activity via different mechanisms, such as by inhibiting bacterial adhesion and enzymes (urease), neutralizing bacterial toxins, suppressing $H$. pylori-induced pathogenic signal transduction pathways at the transcriptional level, modulating the action of the host's immune repertoire and by direct bacteriocidal as well as cytoprotective action (Bonifácio et al., 2014). The aim of this review is to summarize and shed light on the biomedical applications of propolis and other natural products against H. pylori-associated gastrointestinal tract ailments.

\section{Mechanisms of $\boldsymbol{H}$. pylori-induced gastrointestinal tract diseases}

The pathogenic strains of $H$. pylori have an extraordinary capability to survive and develop pathologic manifestations in the most hostile environment of the human stomach. It can survive under strong selective pressure due to the presence of special cagA pathogenicity islands, vacuolating toxin A (VacA toxin), the bacterial IV secretion system and other virulent factors encoded by the OipA, HopQ HopZ (Helicobacter outer membrane proinflammatory proteins), IceA (induced by contact with epithelium), and dupA (duodenal ulcer producing) genes (Cover et al., 1990; Kim, 2016; Odenbreit et al., 2000; Wessler, 2016; Yamaoka et al., 2000). Persistent $H$. pylori infection in the stomach causes chronic gastritis, which eventually leads to peptic ulcers, gastric cell carcinoma and MALT lymphoma, as determined by the severity of infection and degree of inflammation (Blaser and Atherton, 2004;
Naito and Yoshikawa, 2002). On the basis of the presence or absence of cag pathogenicity islands (a genomic fragment of $40 \mathrm{~kb}$ length housing 31 genes), $H$. pylori can be divided into cagPAI positive (more virulent than the latter) and cagPAI negative strains (Tomb et al., 1997). CagPAI encodes the antigenic effector protein CagA and 18 genes required to insert CagA through the bacterial IV secretion system into gastric epithelial cells involved in the development of different pathological conditions (Peek and Blaser, 2002; Viala et al., 2004).

\section{H. pylori-associated gastric inflammation}

H. pylori may cause gastric inflammation by two pathways. First, it inhabits the area under the mucosa layer in close proximity to gastric epithelial cells. It interacts with epithelial cells via its different surface components and causes cellular damage. Second, it inserts different virulent factors into epithelial cells. Both mechanisms trigger specific and nonspecific immune responses along with the secretion of a vast array of immunologic messenger molecules known as cytokines (Bodger and Crabtree, 1998). A number of proinflammatory chemokines orchestrate their functions in $\mathrm{H}$. pylori-mediated gastritis: growth related oncogene alpha (Gro- $\alpha$ ), a monokine induced by IFN-c (CXCL11), IFN-c inducible protein-10 (CXCL-10), regulated on activation normal T cell expressed and secreted (RANTES), CCL20 (MIP-3a/LARC/ exodus), and IL-8 (Eck et al., 2000; Wen et al., 2004; Wu et al., 2007; Yamaoka et al., 1998). H. pylori inserts peptidoglycan into gastric epithelial cells through the bacterial IV secretion system encoded by cagPAI, which upregulates the expression of IL- 8 by stimulating intracellular pathogen recognition receptor Nod1 and thus activating NFKB (nuclear factor kappa B) and AP-1 (activator protein-1) (Allison et al., 2009; Viala et al., 2004). IL-8 is a potent chemoattractant and activator of neutrophils (Hommes et al., 1992). H. pylori activates monocytes and macrophages (resident of lamia propia) through lipopolysaccharide (LPS)-dependent and independent pathways. It also increases the expression of HLA-DR (human leukocyte antigen), IL-2R (interleukin 2 receptor), surface receptors, increased synthesis of IL-1, TNF (tumour necrosis factor) mRNA, different peptides, and ROS (reactive oxygen species) (Mai et al., 1991). IL-1 $\beta$ is a potent inhibitor of the proton pump inducer and recruiter of IL-8 and neutrophils (Dinarello, 1984; March et al., 1985; Noach et al., 1994; Yoshimura et al., 1987). In addition, the neutrophil activating protein of $H$. pylori (HP-NAP) gains entrance into the lamina propria and stimulates the synthesis of chemokines, such as CXCL8, CCL3 and CCL4, to recruit leukocytes at the site of infection (Polenghi et al., 2007). Recruited mast cells are also stimulated in this way by HP-NAP to degranulate different inflammatory molecules (Montemurro et al., 2002). The infiltrating neutrophils significantly damage mucosal cells (Suzuki et al., 1992). Neutrophils secrete different ROS, such as singlet oxygen, superoxide anion, hydroxyl radical, hydrogen peroxide, and hypochlorous, and hence exert oxidative stress on the surrounding tissues and cause damage (Kehrer, 2008). Myeloperoxidase reacts with different ROS that produce hypochlorous acid; then, it reacts with ammonium (produced by urease from $\mathrm{H}$. pylori) and forms monochloroamines that cause DNA fragmentation (Bhattacharjee et al., 2002; Mizuki et al., 2000; Roe et al., 2002). It has been reported that VacA, $\gamma$-glutamyltranspeptidase and cholesteryl $\alpha$-glucosides of $H$. pylori cause Th1, Th17 and Treg-subpopulations of T-lymphocytes to come into play, which intensify the chronicity of inflammation (Beigier-Bompadre et al., 2011).

\section{Peptic ulcers caused by H. pylori}

Peptic ulcers consist of gastric ulcers (accounting for one-third of peptic ulcers) and duodenal ulcers (accounting for the rest) 
(Hopkins et al., 1996). H. pylori produces deleterious enzymes such as proteases, including serine protease high temperature requirement A (HtrA), collagenase Hp0169, catalase, urease, lipases, phospholipases, the cell-translocating serine/threonine kinase (CtkA) and some other potent ulcerogens, as well as platelet activating factor (PAF) and LTB4 (leukotriene B4) (Denizot et al., 1990; Fukuda et al., 1990; Sidebotham et al., 1991; Wessler, 2016). Lu et al. (2005) showed that dupA is found in $42 \%$ of patients with duodenal ulcer. It causes increased antral neutrophil infiltration, IL-8 production and activation of IL-8 promoter specific transcription factors. The cagE gene (also called picB), located within the pathogenicity island, is associated with duodenal ulceration. It also upregulates IL-8 expression (Day et al., 2000). H. pylori may also activate cytoplasmic phospholipase A2 required for arachidonic acid synthesis to produce prostaglandins (Pomorski et al., 2001). Phospholipase A2 is a lipolytic enzyme. It causes inflammation and damage of mucosal cells, eventually leading to peptic ulcer (Langton and Cesareo, 1992). Increased expression of cyclooxygenase 2 (COX 2) occurs in gastric epithelial cells, macrophages and fibroblasts in $H$. pylori-associated gastritis and gastric ulcer. This occurs by the activation of CREB (cAMP responsive element binding protein) and upstream stimulatory factors 1 and 2 (USF-1 and USF-2), which are important transcription factors (Jüttner et al., 2003; Tatsuguchi et al., 2000). H. Pylori decreases the secretion of bicarbonate from epithelial cells; thus, hydrochloric acid cannot be neutralized and affects the gastroduodenal lining excessively due to its vicious nature. In addition, H. pylori infection stimulates the vaso-vagal reflex to increase $\mathrm{H}^{+}$secretion. It has also been shown that the $\mathrm{cag}^{+}$strain of $H$. pylori inhibits the synthesis of mucin. The combination of these factors causes mucosal cell damage and ultimately peptic ulcers (Baik et al., 1996; Konturek et al., 2001).

\section{Gastric carcinoma caused by H. pylori}

Approximately 1-2\% of $H$. pylori-infected patients are at risk of gastric cell carcinoma (Kusters et al., 2006). AID (activation induced cytidine deaminase), a type of DNA-RNA editing enzyme from the cytidine deaminase family expressed in a carefully regulated way in germinal centre B cells, plays a crucial role in somatic hypermutation and class switch recombination in B lymphocytes (Honjo et al., 2002). AID has an ectopic expression pattern in non-lymphoid cells, where it exerts its high mutagenic effect on genes other than the immunoglobulin genes (Yoshikawa et al., 2002). It has been shown that cagPAI positive $H$. pylori induces aberrant expression of AID in gastric epithelial cells in the IкB kinase-dependent NFкB activation pathway, leading to mutations in different genes, especially TP53 (in humans) and Trp53 (in mice) pertaining to gastric cell carcinoma (Matsumoto et al., 2007).

The members of the mitogen activated protein kinase (MAPK) family are highly conserved, ubiquitous signalling protein molecules involved in cell division, differentiation, apoptosis, stress condition, and inflammatory reactions. $\mathrm{Cag}^{+}-\mathrm{H}$. pylori induces the phosphorylation and thus activation of different MAP kinases such as p38, c-Jun N-terminal kinases (JNK), and extracellular signal-regulated kinases (ERK), hence altering the physiology of epithelial gastric cells. $\mathrm{Cag}^{-}$and $\mathrm{cag}^{+}$strains that have a disrupted picB region of cagPAI can also exert these effects to a small extent (Keates et al., 1999).

After entering the cells, CagA protein undergoes tyrosine phosphorylation at the EPIYA motif by enzymes of the SRC kinase family such as YES, FYN, SRC and LYN, indicating its ability to disrupt key signalling pathways leading to transformation (Stein et al., 2002).

The $\mathrm{Cag}^{+}$strain also disrupts the E-cadherin/ $\beta$ catenin signal transduction pathway in gastric epithelial cells, leading to trans- differentiation. It inhibits the formation of the E-cadherin/ $\beta$-catenin complex by binding to E-cadherin, leading to cytosolic and nuclear accumulation of $\beta$-catenin and transactivation of $\beta$-catenindependent genes such as the cdx1 gene (encoding an intestinal specific transcription factor). It also causes dysregulation of various cellular proteins, such as SHP2 phosphatase, Grb2, Zo-1, c-Met, and p21WAF1/cip1, resulting in morphological changes leading to intestinal type metaplasia and intestinal type gastric adenocarcinoma in gastric epithelial cells (Murata-Kamiya et al., 2007).

In addition, Cag positive strains of $H$. pylori upregulate the expression of IL-8 and neutrophil chemotactic factor; for example, GRO- $\alpha$, causing severe pathologic gastroduodenal complexity (Amieva et al., 2003). Increased and persistent loss of gastric epithelial cells leads to atrophic gastritis, loss of gastric glands, and decreased acid secretion. The resulting lower gastric $\mathrm{pH}$ acts as a survival advantage for $H$. pylori. $H$. pylori mediates these by CagASHP2 interaction and the VacA toxin. All strains isolated from humans possess the vacA gene. VacA reduces the transmembrane potential and increases the permeability of host cell mitochondria. Increased mitochondrial membrane permeability triggers the release of cytochrome c. It also reduces ATP concentration and cell proliferation. All of these cause activation of caspase 3 and thus cell death (Galmiche et al., 2000; Hatakeyama, 2004; Schmitt and Haas, 1994; Willhite et al., 2003). H. pylori can also cause DNA damage and apoptosis of gastric epithelial cells and macrophages by increased hydrogen peroxide production by inducing the expression of spermine oxidase, which oxidizes polyamines (Xu et al., 2004). Eventually, the continuous apoptosis of gastric epithelial cells is compensated by rapid cell proliferation and compromises the fidelity of DNA replication. Thus, mutations accumulate in DNA repair genes and tumour suppressor genes and contribute to the morphological transformation of cells, superficial gastritis and intestinal metaplasia (Hatakeyama, 2004). In addition, by phosphorylating the epidermal growth factor receptor, H. pylori inhibits apoptosis of gastric cells burdened with highly damaged DNA, leading to neoplastic transformation of these cells (Yan et al., 2009). H. pylori further compromises the intact genome by blocking the nucleotide excision repair pathway and the mismatch DNA repair pathway by decreasing the level of proteins such as MSH2, MSH6, MSH3, MLH1, PMS1, and PMS2 (Kim et al., 2002; Machado et al., 2009). It also activates some tyrosine kinase receptors, such as EGRR, HER2-Neu (Erb2) and c-Met, which play crucial roles in carcinogenesis (Churin et al., 2003; Keates et al., 2001; Thiery, 2002). It causes increased expression of matrix metalloprotease (MMP) 3, 7 and 9, eventually facilitating the spread of carcinoma (Göõz et al., 2001; Mori et al., 2003; Wroblewski et al., 2003).

\section{MALT lymphoma caused by $\mathrm{H}$. pylori}

H. pylori-induced gastritis can also trigger autoimmunity that may lead to MALT lymphoma (Greiner et al., 1994), a low-grade lymphoma associated with chronic gastritis and lymphoepithelial lesions (Ruskone-Fourmestraux et al., 2001; Sackmann et al., 1997). A chromosomal translocation $\mathrm{t}(11 ; 18)(\mathrm{q} 21$; q21) has been most frequently identified in MALT lymphoma cells involving two genes: apoptosis inhibitor 2 (API1, also called cIAP2), located at 11q21, and the MALT gene, located at 18q21, resulting in the formation of the fusion gene API2-MALT1 (Akagi et al., 1999; Dierlamm et al., 1999). Another translocation event involving the immunoglobulin gene located at $14 \mathrm{q} 32$ and a MALT gene located at 18q21 has also been identified recently in $10 \%$ of cases (Penas et al., 2003). It is hypothesized that the API1-MALT fusion protein plays an antiapoptotic role in the progression of MALT (Hosokawa et al., 2004) since higher expression of miR-142-5p and miR-155 has been detected in MALT lymphoma lesions (Saito et al., 2012). 


\section{Current treatment strategy against $H$. pylori-associated diseases}

To date, different antibiotics, including amoxicillin, clarithromycin, metronidazole, and levofloxacin, and anti-secretory agents, such as proton pump inhibitors (PPIs), are used in the treatment of $H$. pylori-associated gastric ulcers. Nevertheless, the administration of antibiotics is associated with the development of resistance and different side effects, such as diarrhoea, as a result of perturbation of the normal microbiota colonizing the gastrointestinal tract (Yang et al., 2014). To overcome this problem, probiotics, including Saccharomyces boulardii and Lactobacillus strains, have been combined with antibiotics. Although this addition cannot improve the eradication rate of $H$. pylori, it can reduce the antibiotic-associated side effects (Cindoruk et al., 2007; Cremonini et al., 2002; Hurduc et al., 2009; Lu et al., 2016).

Recently, various combinations of antimicrobial agents and PPIs have been designed, such as triple therapy, bismuth-containing quadruple therapy, sequential therapy and concomitant therapy (Smith et al., 2017; Yang et al., 2014). Triple therapy is the combination of two antibiotics (clarithromycin plus metronidazle or amoxicillin) and PPIs (Chey and Wong, 2007; Malfertheiner et al., 2007). Complete eradication and therapeutic success are inversely related to the emergence of $H$. pylori-resistant antibiotics like clarithromycin. Nevertheless, the emergence of clarithromycin-resistant strains is reported to progressively increase in different countries at varying rates (approximately 50\% in China, $40 \%$ in Turkey and 30\% in Italy and Japan). Clarithromycin-PPI containing triple therapy should be used only in those regions where the rate of clarithromycin resistance is less than 15\% (Gatta et al., 2013; Malfertheiner et al., 2016; Thung et al., 2016), with an eradication failure rate of $10-40 \%$ (Abbas et al., 2009; Perna et al., 2007). Even prolonged duration of triple therapy has no remarkable benefits (Calvet et al., 2000).

As an alternative to triple therapy, sequential therapy has been proposed, which involves a simple dual regimen including a PPI plus amoxicillin for the first five days and then a triple regimen for the following five days (Gisbert et al., 2010). The eradication rate of the sequential regimen is nearly $90 \%$, but it is associated with a tendency towards lower efficacy (Gao et al., 2010; Molina-Infante et al., 2010; Paoluzi et al., 2010). In this regard, a non-bismuth quadruple regimen or concomitant regimen has recently been shown to be efficacious. By adding $500 \mathrm{mg}$ of metronidazole or tinidazole twice daily, the traditional triple therapy (PPI-clarithromycin-amoxicillin) can be converted to a more potent therapy (Graham and Shiotani, 2008). In addition to antibiotic-based therapy, phototherapy, the development of a vaccine, a probioticbased diet, and nutraceutical agents are useful alternative methods to treat H. pylori infection (Ayala et al., 2014).

Some phytomedicines are used for the treatment of $H$. pylori infection, such as propolis, green tea catechins, garlic extract and cranberry juice (Vítor and Vale, 2011). Different combinations of the phytomedicines may improve the eradication rate of $H$. pylori to a significant level. Some applications of phytomedicines are described below.

\section{Previous breakthroughs of natural products against $\boldsymbol{H}$. pylori- associated diseases}

Both propolis and different types of natural products, including fruits, vegetables, spices and medicinal plants, oils, essential oil, dairy products, and probiotics, have been observed to ameliorate $H$. pylori-induced gastrointestinal diseases (Fahey et al., 2015; Murali et al., 2014). Many of them show prominent and promising effects. For example, green tea, essential oil of mastic gum, Oyama Magnolia, California Mugwort, and the Kamala tree show strong anti-bactericidal effects against clarithromycin- and metronidazole-resistant $H$. pylori. Patchouli, Chinese goldthread, amur cork, apple, Chinese peony, and Yunnan goldthread have been shown to have anti-H. pylori-urease activity. Pomegranate, okra, mozuku, Aleppo oak, black pepper, and purple mangosteen exert an anti-adhesive activity to gastric epithelial cells of $H$. pylori. In an in vitro study, it has been shown that the eastern black walnut inhibits three important enzymes of $H$. pylori: cystathionine gamma synthase, malonyl-coA-acyl carrier protein transacylase, and $\beta$-hydroxyacyl dehydratase. Turmeric, garlic, celery, apple, potato, sea almond, and bitter ginger have gastroprotective effects, while the swallow root as well as the potato possesses host DNA protective and cytoprotective effects. Some plant products also have potent ameliorating effects on gastric adenocarcinoma induced by $H$. pylori, such as celery, black pepper, liquorice and balsam weed. Ginseng, cheese fruit, chamber bitter, blond plantain, mastic, catmint, and rennet have anti-inflammatory activities induced by H. pylori (Bae et al., 2014; Kong et al., 2008; Park et al., 2014; Tharmalingam et al., 2016). Evidence of findings highlighting the roles of some natural products against $H$. pylori-mediated gastrointestinal diseases is summarized in Table 1.

\section{Emerging adjuvant therapy for $\boldsymbol{H}$. pylori-mediated gastrointestinal diseases: propolis and its constituents}

Propolis contains many compounds, such as chalcones (2, 6dihydroxy-4-methoxychalcone, 2, 4', 6-trihydroxy-4-methoxychalcone); benzoic acid and derivatives (salicylic acid, 4-methoxybenzoic acid, 4-hydroxybenzoic acid, protocatechuic acid, 2amino-3-methoxybenzoic acid, gentisic acid, gallic acid, transconiferyl benzoate, protocatechuic acid, trans-p-coumaryl benzoate, phenylmethyl ester of benzoic and salicylic acid); benzaldehyde derivatives (vanillin, isovanillin); cinnamyl alcohol, cinnamic acid and its derivatives; terpene, sesquiterpene alcohols and their derivatives (geraniol, $\alpha$-acetoxybetulenol, nerolidol, $\beta$-bisabolol, guaicol); sesquiterpene and triterpene hydrocarbons; aliphatic hydrocarbons (eicosane, 1-octadecene, pentacosane, tricosane); sterols and steroid hydrocarbons (cholestrilene, cholinasterol, $\beta$-dihydrofucosterol, stigmasterol, nanosterol); sugars (d-glucose, $\mathrm{d}$-fructose, ribofuranose); other acids and derivatives (methyl ester of 2,8-dimethylundecanoic acid, alnustic acid, sorbic acid, myristic acid, hexadecanoic acid, butyl-2-methylpropyl ester of phthalic acid, methyl ester of phenylmethyl ester of 14-methylpentadecanoic acid); amino acids; and some minerals ( $\mathrm{Na}, \mathrm{K}, \mathrm{Mg}, \mathrm{Zn}, \mathrm{Cd}, \mathrm{Ca}$, $\mathrm{Ba}, \mathrm{Ag}, \mathrm{Ni}, \mathrm{Fe}$ ) (Walker and Crane, 1987). This wide variety of compounds may underlie many biological and pharmacological properties of propolis. The mechanisms of action of propolis have been widely studied using different experimental models in vitro and in vivo. Therefore, as propolis-containing products have been marketed and humans have used propolis for different purposes, researchers have been interested in the investigation of isolated compounds responsible for propolis activity. Here, we designed some strategies at the molecular level to regulate $H$. pylorimediated gastrointestinal diseases via browsing various studies of propolis and its constituents.

Anti-inflammatory effect of propolis to attenuate H. pylori-mediated gastrointestinal diseases

The caffeic acid phenethyl ester (CAPE) of propolis from honeybee hives has anti-inflammatory properties. T-cells, specifically CD4+ cells, play a key role in the initiation of $H$. pyloriassociated gastritis (Eaton et al., 2001). CAPE has an immunosuppressive effect on human T-cells. It is a potent inhibitor of early and late events in T-cell receptor-mediated T-cell activation. CAPE specifically inhibits both IL-2 gene transcription and synthesis in stimulated T-cells. Propolis extracts (especially their different 
Table 1

Evidence from different studies over the last ten years with natural products associated with Helicobacter pylori-mediated gastrointestinal diseases.

\begin{tabular}{|c|c|c|c|c|c|c|c|c|}
\hline No. & $\begin{array}{l}\text { Natural } \\
\text { Products }\end{array}$ & Active Compounds & Plant parts & Type of study & $\begin{array}{l}\text { Dose and } \\
\text { Duration }\end{array}$ & Country & $\begin{array}{l}\text { Findings of respective } \\
\text { study }\end{array}$ & References \\
\hline 1. & $\begin{array}{l}\text { Panax ginseng } \\
\text { (Meyer) }\end{array}$ & Ginsenosides & Root & $\begin{array}{l}\text { In vivo study } \\
\text { in } \\
\text { experimental } \\
\text { rat model } \\
\text { (Mongolian } \\
\text { gerbils) }\end{array}$ & $\begin{array}{l}200 \mathrm{mg} / \mathrm{rat} \text { of } \\
40 \mathrm{~g} \text { body weight } \\
\text { for } 6 \text { weeks }\end{array}$ & Korea & $\begin{array}{l}\text { Exerts anti-inflam- } \\
\text { matory effect on } H \text {. } \\
\text { pylori-induced gas- } \\
\text { tric mucosal cells by } \\
\text { downregulating i- } \\
\text { NOS, IL-1 } \beta \text {, and ker- } \\
\text { atinocyte chemoat- } \\
\text { tractant factor, } \\
\text { suppressing LPO lev- } \\
\text { el and MPO activity }\end{array}$ & (Bae et al., 2014) \\
\hline 2. & Propolis & - & $\begin{array}{l}\text { Ethanolic and } \\
\text { propylene } \\
\text { glycol extract }\end{array}$ & In vitro & MIC: $6-14 \mathrm{mg} / \mathrm{ml}$ & $\begin{array}{l}\text { Basque } \\
\text { country } \\
\text { (Northern } \\
\text { Spain) }\end{array}$ & - Anti-H. pylori activity & $\begin{array}{l}\text { (Bonvehí and } \\
\text { Gutiérrez, 2012) }\end{array}$ \\
\hline \multirow[t]{2}{*}{3.} & $\begin{array}{l}\text { Curcuma longa } \\
\text { (Turmeric) }\end{array}$ & $\begin{array}{l}\text { Curcumin (diferuloyl- } \\
\text { methane) }\end{array}$ & Rhizome & In vitro & $\begin{array}{l}\text { Minimum } \\
\text { inhibitory } \\
\text { concentration } \\
\text { (MIC): } 5-50 \mu \mathrm{g} / \\
\mathrm{ml}\end{array}$ & India & $\begin{array}{l}\text { - Potent anti-bacterial } \\
\text { activity } \\
\text { - Healing of } H \text {. pylori- } \\
\text { induced gastric dam- } \\
\text { age }\end{array}$ & (De et al., 2009) \\
\hline & & & & $\begin{array}{l}\text { In vivo study } \\
\text { in } \\
\text { experimental } \\
\text { rat model }\end{array}$ & $\begin{array}{l}25 \mathrm{mg} / \mathrm{kg} \text { once } \\
\text { daily for } 7 \text { days }\end{array}$ & & & \\
\hline 4. & $\begin{array}{l}\text { Morinda } \\
\text { citrifolia } \\
\text { (Cheese fruit) }\end{array}$ & - & Fruit extract & Ex vivo & - & Taiwan & $\begin{array}{l}\text { - Lower expression of } \\
\text { CagA, COX-2, IL-8, i- } \\
\text { NOS; } \\
\text { - Inhibition of bacterial } \\
\text { adhesion to AGS cells } \\
\text { and neutrophil che- } \\
\text { motaxis }\end{array}$ & (Huang et al., 2014) \\
\hline 5. & $\begin{array}{l}\text { Allium sativum } \\
\text { (Garlic) }\end{array}$ & allyl/methyl sulfides & Oil & Ex vivo & - & UK & $\begin{array}{l}\text { - Preventive effect } \\
\text { against H. pylori-in- } \\
\text { duced gastritis and } \\
\text { thus gastric cancer }\end{array}$ & $\begin{array}{l}\text { (O'Gara et al., } \\
2008)\end{array}$ \\
\hline \multirow[t]{2}{*}{6.} & $\begin{array}{l}\text { Phyllanthus } \\
\text { urinaria L. } \\
\text { (Chamber } \\
\text { bitter) }\end{array}$ & $\begin{array}{l}\text { Phyllanthin, Phyltetralin, } \\
\text { Trimethyl 3,4- } \\
\text { dehydrochebulate, } \\
\text { Methylgallate, Rhamnocitrin, } \\
\text { Methyl brevifolincarboxylate, }\end{array}$ & $\begin{array}{l}\text { Extract of the } \\
\text { entire plant }\end{array}$ & $\begin{array}{l}\text { Ex vivo, In } \\
\text { vitro }\end{array}$ & $\begin{array}{l}\text { MBC (crude } \\
\text { extract): } 97.7 \mu \mathrm{g} / \\
\text { ml }\end{array}$ & Taiwan & $\begin{array}{l}\text { - Blocking the activa- } \\
\text { tion of NF-кB in- } \\
\text { duced by H. pylori } \\
\text { and the consequent } \\
\text { release of IL-8, bac- } \\
\text { terial attachment } \\
\text { and attack of AGS } \\
\text { cells by a crude } \\
\text { chloroform extract }\end{array}$ & (Lai et al., 2008) \\
\hline & & $\begin{array}{l}\text { Quercetin-3- } \alpha-\mathrm{L}- \\
\text { rhamnopyranoside, } \\
\beta \text {-sitosterol 3-O- } \beta \text {-D- } \\
\text { glucopyranoside, } \\
\text { Rutin }\end{array}$ & & & & & & \\
\hline \multirow[t]{2}{*}{7.} & $\begin{array}{l}\text { Ageratum } \\
\text { conyzoides }\end{array}$ & - & Whole plant & In vitro & $\begin{array}{l}\text { MIC: } 0.063-1.0 \\
\mathrm{mg} / \mathrm{ml}\end{array}$ & Cameroon & $\begin{array}{l}\text { - Potent antibacterial } \\
\text { effect }\end{array}$ & (Ndip et al., 2007) \\
\hline & & & & & $\begin{array}{l}\text { MBC: } 0.098-12.5 \\
\mathrm{mg} / \mathrm{ml}\end{array}$ & & & \\
\hline 8. & $\begin{array}{l}\text { Scleria } \\
\text { striatinux }\end{array}$ & - & Roots & & $\begin{array}{l}\text { MIC: } 0.032-1.0 \\
\mathrm{mg} / \mathrm{ml} \\
\mathrm{MBC}: 0.098-15.0 \\
\mathrm{mg} / \mathrm{ml}\end{array}$ & & & \\
\hline \multirow[t]{2}{*}{9.} & $\begin{array}{l}\text { Lycopodium } \\
\text { cernua } \\
\text { (Staghorn } \\
\text { clubmoss) }\end{array}$ & - & Whole plant & & $\begin{array}{l}\text { MIC: } 0.063-0.5 \\
\mathrm{mg} / \mathrm{ml}\end{array}$ & & & \\
\hline & & & & & $\begin{array}{l}\text { MBC: } 0.195-12.5 \\
\mathrm{mg} / \mathrm{ml}\end{array}$ & & & \\
\hline 10. & $\begin{array}{l}\text { Acanthus } \\
\text { montanus } \\
\text { (Mountain } \\
\text { thistle) }\end{array}$ & - & $\begin{array}{l}\text { Leaves and } \\
\text { stalk }\end{array}$ & & - & & $\begin{array}{l}\text { Have antibacterial } \\
\text { activity but not so } \\
\text { potent }\end{array}$ & \\
\hline 11. & $\begin{array}{l}\text { Aulutandria } \\
\text { kamerunensis }\end{array}$ & - & Rhizomes & & - & & & \\
\hline 12. & $\begin{array}{l}\text { Tapeinochilos } \\
\text { ananassae }\end{array}$ & - & Rhizomes & & - & & & \\
\hline
\end{tabular}


Table 1 (Continued)

\begin{tabular}{|c|c|c|c|c|c|c|c|c|}
\hline No. & $\begin{array}{l}\text { Natural } \\
\text { Products }\end{array}$ & Active Compounds & Plant parts & Type of study & $\begin{array}{l}\text { Dose and } \\
\text { Duration }\end{array}$ & Country & $\begin{array}{l}\text { Findings of respective } \\
\text { study }\end{array}$ & References \\
\hline 13. & Ephorbia hirta & - & Whole plant & & - & & & \\
\hline 14. & Emilia coccinea & - & Whole plant & & - & & & \\
\hline 15. & $\begin{array}{l}\text { Scleria } \\
\text { verrucosa }\end{array}$ & - & Roots & & - & & & \\
\hline 16. & $\begin{array}{l}\text { Combretum } \\
\text { molle (Velvet } \\
\text { bush willow) }\end{array}$ & - & Plant extract & In vitro & $\begin{array}{l}\text { MIC: } 0.08-2.50 \\
\mathrm{mg} / \mathrm{ml} \text { (acetone } \\
\text { extract) }\end{array}$ & $\begin{array}{l}\text { South } \\
\text { Africa }\end{array}$ & $\begin{array}{l}\text { - Significant bacteri- } \\
\text { cidal activity }\end{array}$ & (Njume et al., 2011) \\
\hline 17. & $\begin{array}{l}\text { Sclerocarya } \\
\text { birrea (Marula) }\end{array}$ & - & & & $\begin{array}{l}\text { MIC:0.06-2.50 } \\
\mathrm{mg} / \mathrm{ml} \text { (acetone } \\
\text { extract) }\end{array}$ & & & \\
\hline 18. & $\begin{array}{l}\text { Garcinia kola } \\
\text { (Bitter kola) }\end{array}$ & Flavonoids, Tannins & Seeds & In vitro & - & & & \\
\hline \multirow[t]{2}{*}{19.} & $\begin{array}{l}\text { Apium } \\
\text { graveolens } \\
\text { (celery) }\end{array}$ & $\begin{array}{l}\text { Compound with anti-H. pylori } \\
\text { activity }(\mathrm{CAH})(\text { Molecular } \\
\text { weight }=384.23 \text {; empirical } \\
\text { formula } \mathrm{C}_{24} \mathrm{H}_{32} \mathrm{O}_{4} \text { ) }\end{array}$ & Seeds & In vitro & $\begin{array}{l}\text { MIC: } 3.15 \mathrm{mg} / \mathrm{ml} \text {; } \\
\text { MBC: } 6.25-12.5 \\
\mathrm{mg} / \mathrm{ml}\end{array}$ & Australia & - Bactericidal effect & (Zhou et al., 2009) \\
\hline & & Apigenin & $\begin{array}{l}\text { Commercially } \\
\text { purchased }\end{array}$ & In vivo & $\begin{array}{l}60 \mathrm{mg} / \mathrm{kg} \text { body } \\
\text { weight/day for } \\
25 \text { weeks and } 45 \\
\text { weeks in case of } \\
\text { atrophic gastritis } \\
\text { and gastric } \\
\text { cancer group, } \\
\text { respectively }\end{array}$ & $\begin{array}{l}\text { Oriental } \\
\text { countries }\end{array}$ & $\begin{array}{l}\text { - Potent inhibitory ef- } \\
\text { fect on } H \text {. pylori-in- } \\
\text { duced atrophic } \\
\text { gastritis and gastric } \\
\text { cancer manifesta- } \\
\text { tions }\end{array}$ & (Kuo et al., 2014) \\
\hline 20. & $\begin{array}{l}\text { Aegle marmelos } \\
\text { L. (Bael) }\end{array}$ & - & $\begin{array}{l}\text { Methanolic } \\
\text { extract of } \\
\text { unripe fruit }\end{array}$ & $\begin{array}{l}\text { In vivo study } \\
\text { on Sprague } \\
\text { Dawley (SD) } \\
\text { rats }\end{array}$ & $\begin{array}{l}25-500 \mathrm{mg} / \mathrm{kg} \\
\text { for } 10 \text { days }\end{array}$ & India & $\begin{array}{l}\text { - Antioxidative and } \\
\text { anti-ulcerative effect } \\
\text { against HP-LPS in- } \\
\text { duced gastric ulcer }\end{array}$ & $\begin{array}{l}\text { (Ramakrishna } \\
\text { et al., 2015) }\end{array}$ \\
\hline 21. & $\begin{array}{l}\text { Punica } \\
\text { granatum } \\
\text { (Pomegranate) }\end{array}$ & $\begin{array}{l}\text { Tannin (25\%), Ellagitannin, } \\
\text { Punicalagin }\end{array}$ & Fruit & In vitro & $\begin{array}{l}\text { MIC: } 0.8 \mathrm{mg} / \mathrm{ml} \\
\text { MBC: } 3.1 \mathrm{mg} / \mathrm{ml}\end{array}$ & Australia & $\begin{array}{l}\text { - Both antibacterial } \\
\text { and bactericidal ac- } \\
\text { tivity. } \\
\text { - Eradication from } \\
\text { stomach by means of } \\
\text { altering H. pylori- } \\
\text { surface hydropho- } \\
\text { bicity }\end{array}$ & $\begin{array}{l}\text { (Voravuthikunchai } \\
\text { et al., 2006; } \\
\text { Voravuthikunchai } \\
\text { and Mitchell, 2008) }\end{array}$ \\
\hline 22. & $\begin{array}{l}\text { Abelmoschus } \\
\text { esculentus } \\
\text { (Okra) }\end{array}$ & $\begin{array}{l}\text { Carbohydrate-containing } \\
\text { compounds, } \\
\text { Galactoxyloglycan }\end{array}$ & Fruit & In vitro & - & Germany & $\begin{array}{l}\text { - Antiadhesive activity } \\
\text { - Blocking effect on } H \text {. } \\
\text { pylori-surface recep- } \\
\text { tors }\end{array}$ & $\begin{array}{l}\text { (Lengsfeld et al., } \\
\text { 2004) }\end{array}$ \\
\hline 23. & $\begin{array}{l}\text { Curcuma longa } \\
\text { (turmeric) }\end{array}$ & Curcumin & Rhizome & Ex vivo & - & Japan & $\begin{array}{l}\text { - Has inhibitory effect, } \\
\text { most likely by che- } \\
\text { mopreventive mech- } \\
\text { anism } \\
\text { - Suppresses H. pylori- } \\
\text { induced cytidine de- } \\
\text { aminase in gastric } \\
\text { epithelial cells }\end{array}$ & (Zaidi et al., 2009a) \\
\hline 24. & $\begin{array}{l}\text { Camellia } \\
\text { sinensis (Green } \\
\text { tea) }\end{array}$ & $\begin{array}{l}\text { Catechin compounds } \\
\text { (epigallocatechin-3-gallate) }\end{array}$ & $\begin{array}{l}\text { Leaves and } \\
\text { buds }\end{array}$ & In vitro & $\begin{array}{l}\mathrm{MIC}_{90}: 100 \mu \mathrm{g} / \\
\mathrm{ml}\end{array}$ & Japan & $\begin{array}{l}\text { - Strong growth inhi- } \\
\text { biting activity of CLR } \\
\text { and MTZ resistant } H \text {. } \\
\text { pylori. } \\
\text { - Synergistic effect } \\
\text { with AMX }\end{array}$ & $\begin{array}{l}\text { (Yanagawa et al., } \\
\text { 2003) }\end{array}$ \\
\hline \multirow[t]{2}{*}{25.} & $\begin{array}{l}\text { Zingiber } \\
\text { officinale } \\
\text { (Ginger) }\end{array}$ & $\begin{array}{l}\text { 6-Gingerol, 8-Gingerol, 10- } \\
\text { Gingerol, 6-Shogaol and } \\
\text { phenolic acids such as } \\
\text { Cinnamic, Caffeic, Ferulic, } \\
\text { Syringic, p-Coumaric, } \\
\text { Protocatechuic, Gentisic, } \\
\text { Gallic acids }\end{array}$ & Rhizome & In vitro & $\begin{array}{l}\text { MIC: } 10-160 \mu \mathrm{g} / \\
\text { ml depending on } \\
\text { different H. pylori } \\
\text { strains }\end{array}$ & Italy & $\begin{array}{l}\text { Synergistic effect } \\
\text { along with antibio- } \\
\text { tics in ameliorating } \\
\text { H. pylori-associated } \\
\text { gastroduodenal dis- } \\
\text { eases }\end{array}$ & $\begin{array}{l}\text { (Nostro et al., } \\
\text { 2006) }\end{array}$ \\
\hline & $\begin{array}{l}\text { Zingiber } \\
\text { officinale } \\
+ \text { clarithromicin }\end{array}$ & - & & In vitro & $\begin{array}{l}\sum \text { FIC (CLR } \\
\text { susceptible and } \\
\text { resistant } H . \\
\text { pylori): } 0.12-8 \\
\text { and } 0.25-2.03\end{array}$ & Italy & $\begin{array}{l}\text { - Synergistic or addi- } \\
\text { tive anti-H. pylori ef- } \\
\text { fect }\end{array}$ & $\begin{array}{l}\text { (Nostro et al., } \\
2006 \text { ) }\end{array}$ \\
\hline 26. & $\begin{array}{l}\text { Vitis } \\
\text { rotundifolia } \\
\text { (Muscadine } \\
\text { grape) }\end{array}$ & $\begin{array}{l}\text { Polyphenols such as } \\
\text { Quercetin, Resveratrol }\end{array}$ & Thick skin & In vitro & $\begin{array}{l}\text { MIC of quercitin: } \\
256 \mu \mathrm{g} / \mathrm{ml} \text {; MIC } \\
\text { of resveratrol: } \\
128 \mu \mathrm{g} / \mathrm{ml}\end{array}$ & USA & $\begin{array}{l}\text { Bactericidal activity } \\
\text { by means of inter- } \\
\text { acting with bacterial } \\
\text { intracellular compo- } \\
\text { nents }\end{array}$ & $\begin{array}{l}\text { (Brown and Jiang, } \\
\text { 2013) }\end{array}$ \\
\hline
\end{tabular}


Table 1 (Continued)

\begin{tabular}{|c|c|c|c|c|c|c|c|c|}
\hline No. & $\begin{array}{l}\text { Natural } \\
\text { Products }\end{array}$ & Active Compounds & Plant parts & Type of study & $\begin{array}{l}\text { Dose and } \\
\text { Duration }\end{array}$ & Country & $\begin{array}{l}\text { Findings of respective } \\
\text { study }\end{array}$ & References \\
\hline 27. & $\begin{array}{l}\text { Malus } \\
\text { domestica } \\
\text { (Apple) }\end{array}$ & $\begin{array}{l}\text { Facilitating in the synthesis of } \\
\text { different functional by } \\
\text { products } \\
\text { extract of apple peel APPE } \\
\text { ( } 60 \% \text { of total polyphenols; } \\
58 \% \text { of flavonoids; } 30 \% \text { of } \\
\text { flavan-3-ols and } \\
\text { procyanidins) }\end{array}$ & Peel & In vitro & - & Chile & $\begin{array}{l}\text { - Reversible inhibitory } \\
\text { effect on H. pylori- } \\
\text { urease } \\
\text { - Protective effect on } \\
\text { gastric mucosa by } \\
\text { the inhibition of re- } \\
\text { spiratory burst by } \\
\text { neutrophils induced } \\
\text { by } H \text {. pylori }\end{array}$ & $\begin{array}{l}\text { (Pastene et al., } \\
\text { 2009a,b) }\end{array}$ \\
\hline 28. & $\begin{array}{l}\text { Olea europaea } \\
\text { (Virgin olive } \\
\text { oil) }\end{array}$ & $\begin{array}{l}\text { Phenolics with dialdehydic } \\
\text { structure }\end{array}$ & - & Clinical trial & $\begin{array}{l}30 \mathrm{~g} \text { of washed } \\
\text { and unwashed } \\
\text { virgin olive oil for } \\
14 \text { days with an } \\
\text { interval of } 1 \\
\text { month to } H \text {. } \\
\text { pylori infected } \\
\text { subjects }\end{array}$ & Spain & $\begin{array}{l}\text { - Increased eradica- } \\
\text { tion from stomach }\end{array}$ & (Castro et al., 2012) \\
\hline 29. & $\begin{array}{l}\text { Vaccinium } \\
\text { macrocarpon } \\
\text { (cranberry) }\end{array}$ & Polyphenol compounds & Fruit & In vitro & - & $\begin{array}{l}\text { North } \\
\text { America }\end{array}$ & - Bacteriostatic activity & $\begin{array}{l}\text { (Matsushima et al., } \\
\text { 2008) }\end{array}$ \\
\hline 30. & $\begin{array}{l}\text { Brassica } \\
\text { oleracea } \\
\text { (Broccoli) }\end{array}$ & Isothiocyanate sulforaphane & Sprout & Clinical trial & $\begin{array}{l}70 \mathrm{~g} / \text { day for } 8 \\
\text { weeks }\end{array}$ & Japan & $\begin{array}{l}\text { - Bactericidal and } \\
\text { chemoprotective ac- } \\
\text { tivity, } \\
\text { - Counteracting effect } \\
\text { on gastric tumour } \\
\text { formation by upre- } \\
\text { gulating antioxidant } \\
\text { enzymes. }\end{array}$ & $\begin{array}{l}\text { (Yanaka et al., } \\
\text { 2009) }\end{array}$ \\
\hline 31. & $\begin{array}{l}\text { Acacia nilotica } \\
\text { (Babul) }\end{array}$ & $\begin{array}{l}\text { Phenolics, Alkaloids, } \\
\text { Terpenes, Flavonoids, Tannins }\end{array}$ & $\begin{array}{l}\text { Leaves and } \\
\text { flowers }\end{array}$ & In vitro & $\begin{array}{l}\text { MIC (acetone } \\
\text { extract): 16-32 } \\
\mu \mathrm{g} / \mathrm{ml} \text {; MIC } \\
\text { (methanol } \\
\text { extract): 32-64 } \\
\mu \mathrm{g} / \mathrm{ml}\end{array}$ & Pakistan & $\begin{array}{l}\text { - Significant inhibitory } \\
\text { activity }\end{array}$ & (Amin et al., 2013) \\
\hline 32. & $\begin{array}{l}\text { Calotropis } \\
\text { procera (Sodom } \\
\text { apple) }\end{array}$ & - & $\begin{array}{l}\text { Leaves, } \\
\text { flowers }\end{array}$ & In vitro & $\begin{array}{l}\text { MIC (acetone \& } \\
\text { methanol } \\
\text { extract): 8-64 } \\
\mu \mathrm{g} / \mathrm{ml}\end{array}$ & Pakistan & $\begin{array}{l}\text { - Significant inhibitory } \\
\text { activity }\end{array}$ & (Amin et al., 2013) \\
\hline 33. & $\begin{array}{l}\text { Paeonia } \\
\text { lactiflora } \\
\text { (Chinese } \\
\text { peony) }\end{array}$ & $\begin{array}{l}\text { Paeonol, Benzoic acid, } \\
\text { specifically } 1,2,3,4,6 \text {-penta- } \\
\text { O-galloyl- } \beta \text {-D-glucopyranose }\end{array}$ & Root, stem & In vitro & $\begin{array}{l}\text { MIC values of } \\
\text { different active } \\
\text { compounds } \\
\text { range from } 60 \text { to } \\
320 \mathrm{mg} / \mathrm{ml} \\
\text { depending on } H \text {. } \\
\text { pylori strains }\end{array}$ & - & $\begin{array}{l}\text { - Growth inhibiting, } \\
\text { bactericidal, } \\
\text { - Inhibitory effect on } \\
\text { urease of } H \text {. pylori }\end{array}$ & (Ngan et al., 2012) \\
\hline 34. & $\begin{array}{l}\text { Allium sativum } \\
\text { (Garlic) }\end{array}$ & $\begin{array}{l}\text { Allicin, Diallyl sulphur } \\
\text { components }\end{array}$ & Bulb & Ex vivo & $\begin{array}{l}\text { Anti-H. pylori } \\
\text { dose: } 32 \mu \mathrm{g} / \mathrm{ml}\end{array}$ & UK & $\begin{array}{l}\text { - Substantial anti } H \text {. } \\
\text { pylori activity but } \\
\text { decreased in pres- } \\
\text { ence of food }\end{array}$ & $\begin{array}{l}\text { (O’Gara et al., } \\
2008 \text { ) }\end{array}$ \\
\hline 35. & $\begin{array}{l}\text { Quercus } \\
\text { infectoria } \\
\text { (Aleppo oak) }\end{array}$ & - & Fruit & In vitro & $\begin{array}{l}\text { MIC: } 3.12-6.25 \\
\mathrm{mg} / \mathrm{ml} ; \mathrm{MBC}: \\
3.12-12.5 \mathrm{mg} / \mathrm{ml}\end{array}$ & Australia & $\begin{array}{l}\text { Both antibacterial and } \\
\text { bactericidal activity. } \\
\text { - Eradication from } \\
\text { stomach by means of } \\
\text { altering } H \text {. pylori-sur- } \\
\text { face hydrophobicity }\end{array}$ & $\begin{array}{l}\text { (Voravuthikunchai } \\
\text { et al., 2006) }\end{array}$ \\
\hline 36. & $\begin{array}{l}\text { Decalepis } \\
\text { hamiltonii } \\
\text { (Swallow root) }\end{array}$ & $\begin{array}{l}\text { 2-Hydroxy-4-methoxy } \\
\text { benzaldehyde (HMBA) }\end{array}$ & Root & In vitro & MIC: $\sim 39 \mu \mathrm{g} / \mathrm{ml}$ & India & $\begin{array}{l}\text { - Bacterial cell lysis. } \\
\text { - Host DNA protective } \\
\text { effect by binding to } \\
\text { DNA and protein. } \\
\text { - Counteracting effect } \\
\text { of VacA }\end{array}$ & $\begin{array}{l}\text { (Srikanta et al., } \\
\text { 2011) }\end{array}$ \\
\hline 37. & $\begin{array}{l}\text { Pinus koraiensis } \\
\text { Siebol et Zucc }\end{array}$ & $\begin{array}{l}\text { Syringic acid, p-Coumaric } \\
\text { acid }\end{array}$ & Leaves & In vitro & - & Korea & $\begin{array}{l}\text { - Potent anti } H \text {. pylori } \\
\text { activity }\end{array}$ & (Jo and Cho, 2016) \\
\hline 38. & $\begin{array}{l}\text { Gymnosperma } \\
\text { glutinosum } \\
\text { (Gum head) }\end{array}$ & - & Leaves & In vitro & - & - & $\begin{array}{l}\text { - Growth inhibitory ac- } \\
\text { tivity }\end{array}$ & $\begin{array}{l}\text { (Gomez-Flores } \\
\text { et al., 2016) }\end{array}$ \\
\hline 39. & $\begin{array}{l}\text { Cratoxylum } \\
\text { arborescens }\end{array}$ & $\beta$-Mangostin (BM) & Stem bark & In vitro & $\begin{array}{l}\text { MIC: } 250 \mu \mathrm{g} / \mathrm{ml} \text {; } \\
\text { MBC: }>250 \mu \mathrm{g} / \\
\mathrm{ml}\end{array}$ & Malaysia & $\begin{array}{l}\text { - Growth inhibitory } \\
\text { activity }\end{array}$ & $\begin{array}{l}\text { (Sidahmed et al., } \\
\text { 2016) }\end{array}$ \\
\hline
\end{tabular}


Table 1 (Continued)

\begin{tabular}{|c|c|c|c|c|c|c|c|c|}
\hline No. & $\begin{array}{l}\text { Natural } \\
\text { Products }\end{array}$ & Active Compounds & Plant parts & Type of study & $\begin{array}{l}\text { Dose and } \\
\text { Duration }\end{array}$ & Country & $\begin{array}{l}\text { Findings of respective } \\
\text { study }\end{array}$ & References \\
\hline 40. & $\begin{array}{l}\text { Pogostemon } \\
\text { cablin (Blanco) } \\
\text { Benth } \\
\text { (Labiatae) } \\
\text { (Herba } \\
\text { pogostemonis) }\end{array}$ & $(-)$ - Patchouli alcohol (PA) & Aerial parts & Ex vivo & $\begin{array}{l}\text { Pretreatment of } \\
\text { cells with PA at } \\
\text { concentrations of } \\
5,10,20 \mu \mathrm{m}\end{array}$ & China & $\begin{array}{l}\text { - Gastroprotective ef- } \\
\text { fect against } H \text {. pylori- } \\
\text { urease induced cyto- } \\
\text { toxicity via its anti- } \\
\text { oxidative, anti- } \\
\text { inflammatory, anti- } \\
\text { apoptotic, antioxida- } \\
\text { tive and } \\
\text { - H. pylori-urease in- } \\
\text { hibitory actions }\end{array}$ & (Xie et al., 2016) \\
\hline 41. & $\begin{array}{l}\text { Rumex } \\
\text { aquaticus Herba }\end{array}$ & $\begin{array}{l}\text { Quercetin-3-O- } \beta \text {-D- } \\
\text { glucuronopyranoside (ECQ) }\end{array}$ & Plant extract & Ex vivo & - & Korea & $\begin{array}{l}\text { - Down regulates the } \\
\text { expression of proin- } \\
\text { flammatory cytokines } \\
\text { in } H \text {. pylori-infected } \\
\text { gastric epithelial cells }\end{array}$ & (Han et al., 2016) \\
\hline 42. & $\begin{array}{l}\text { Hericium } \\
\text { erinaceus (Bull.) } \\
\text { (Fungus) }\end{array}$ & $\begin{array}{l}\text { 1-(5-chloro-2- } \\
\text { hydroxyphenyl)-3-methyl-1- } \\
\text { butanone and 2,5-bis } \\
\text { (methoxycarbonyl) } \\
\text { terephthalic acid }\end{array}$ & Fruiting body & In vitro & $\begin{array}{l}\text { MIC: } 12.5-400 \\
\mu \mathrm{g} / \mathrm{ml}\end{array}$ & China & $\begin{array}{l}\text { - Growth inhibitory ac- } \\
\text { tivity }\end{array}$ & (Liu et al., 2016) \\
\hline 43. & $\begin{array}{l}\text { Piper nigrum } \\
\text { (Black pepper) }\end{array}$ & Piperine & - & Ex vivo & - & - & $\begin{array}{l}\text { - Counteracting } H \text {. py- } \\
\text { lori infection via re- } \\
\text { duced breakdown and } \\
\text { downregulation of } H \text {. } \\
\text { pylori-induced } \\
\beta \text {-catenin expression, } \\
\text { - Blockage of bacterial } \\
\text { adhesion and entry of } \\
\text { vacA and cagA toxin, } \\
\text { - Reduced secretion of } \\
\text { IL-8 from } H \text {. pylori- } \\
\text { infected gastric epi- } \\
\text { thelium, thus amelio- } \\
\text { rating risk of } \\
\text { oncogenesis }\end{array}$ & $\begin{array}{l}\text { (Tharmalingam } \\
\text { et al., 2016) }\end{array}$ \\
\hline 44. & $\begin{array}{l}\text { Solanum } \\
\text { tuberosum } \\
\text { (potato) }\end{array}$ & $\begin{array}{l}\text { Potato galactan } \\
\text { polysaccharide (PGP) }\end{array}$ & Tuber & $\begin{array}{l}\text { In vivo } \\
\text { (Wistar } \\
\text { albino rat) } \\
\text { In vitro }\end{array}$ & $\begin{array}{l}\text { Pretreatment for } \\
14 \text { days at } 100 \\
\text { and } 200 \mathrm{mg} / \mathrm{kg} \\
\text { body weight } \\
\text { IC } 50 \text { against } \mathrm{H}^{+} / \\
\mathrm{K}^{+}-\mathrm{ATPase}: 420 \\
\mu \mathrm{g} / \mathrm{ml}\end{array}$ & India & $\begin{array}{l}\text { - Growth inhibitory } \\
\text { effect on } H \text {. pylori. } \\
\text { - Gastroprotective ef- } \\
\text { fect against gastric } \\
\text { ulcer associated with } \\
\mathrm{H}^{+} / \mathrm{K}^{+} \text {-ATPase inhibi- } \\
\text { tory activity, } \\
\text { - DNA and cytopro- } \\
\text { tectivity. }\end{array}$ & $\begin{array}{l}\text { (Chandrashekar } \\
\text { and Dharmesh, } \\
\text { 2016) }\end{array}$ \\
\hline \multirow[t]{2}{*}{45.} & $\begin{array}{l}\text { Glycyrrhiza } \\
\text { glabra } \\
\text { (Liquorice) }\end{array}$ & $\begin{array}{l}\text { 18ß-Glycyrrhetinic acid } \\
\text { (GRA) Licochalcone A }\end{array}$ & Roots & $\begin{array}{l}\text { In vivo } \\
\text { (Mongolian } \\
\text { gerbils) }\end{array}$ & $\begin{array}{l}0.1 \% \text { GRA } \\
\text { dissolved with } \\
\text { drinking water } \\
\text { for } 8 \text { weeks }\end{array}$ & China & $\begin{array}{l}\text { - Ameliorating effect } \\
\text { on } H \text {. pylori-induced } \\
\text { gastritis. } \\
\text { - No significant differ- } \\
\text { ence between anti- } \\
\text { biotic-treated groups } \\
\text { and GRA-treated } \\
\text { group. }\end{array}$ & (Cao et al., 2016) \\
\hline & & & Roots & $\begin{array}{l}\text { In vivo (IL-10 } \\
\text { deficient } \\
\text { mice) }\end{array}$ & $\begin{array}{l}25,50,100 \mathrm{mg} / \mathrm{kg} \\
\text { body weight for } \\
24 \text { weeks }\end{array}$ & Korea & $\begin{array}{l}\text { Amelioration of } H \text {. } \\
\text { pylori-induced gas- } \\
\text { tric neoplasia by } \\
\text { acting on transcrip- } \\
\text { tion }\end{array}$ & (Park et al., 2014) \\
\hline 46. & $\begin{array}{l}\text { Eryngium } \\
\text { foetidum } \\
\text { (Culantro) }\end{array}$ & - & Leaves & $\begin{array}{l}\text { In vitro } \\
\text { In vivo (Swiss } \\
\text { mice) }\end{array}$ & $\begin{array}{l}\text { MIC: } 64 \mu \mathrm{g} / \mathrm{ml} \\
500 \mathrm{mg} / \mathrm{kg} \text { body } \\
\text { weight/day for } \\
7 \text { days }\end{array}$ & Cameroon & $\begin{array}{l}\text { - Potent anti-H. pylori } \\
\text { activity }\end{array}$ & $\begin{array}{l}\text { (Eyoum Bille and } \\
\text { Nguepi, 2016) }\end{array}$ \\
\hline 47. & $\begin{array}{l}\text { Coptis chinensis } \\
\text { (Chinese } \\
\text { goldthread) }\end{array}$ & $\begin{array}{l}\text { Berberine along with } \\
\text { different alkaloids }\end{array}$ & Rhizome & In vitro & $\begin{array}{l}\mathrm{IC}_{50}: 0.58 \pm 0.03 \\
\mathrm{mg} / \mathrm{ml}\end{array}$ & China & $\begin{array}{l}\text { Reversible, non-com- } \\
\text { petitive, concentra- } \\
\text { tion and time } \\
\text { dependent inhibitory } \\
\text { effect on } H \text {. pylori- } \\
\text { urease by interacting } \\
\text { with sulfhydryl group } \\
\text { at the active site of } \\
\text { urease }\end{array}$ & (Li et al., 2016) \\
\hline
\end{tabular}


Table 1 (Continued)

\begin{tabular}{|c|c|c|c|c|c|c|c|c|}
\hline No. & $\begin{array}{l}\text { Natural } \\
\text { Products }\end{array}$ & Active Compounds & Plant parts & Type of study & $\begin{array}{l}\text { Dose and } \\
\text { Duration }\end{array}$ & Country & $\begin{array}{l}\text { Findings of respective } \\
\text { study }\end{array}$ & References \\
\hline 48. & $\begin{array}{l}\text { Coptis teeta } \\
\text { (Yunnan } \\
\text { goldthread) }\end{array}$ & $\begin{array}{l}\text { Berberine along with } \\
\text { different alkaloids }\end{array}$ & Rhizomes & In vitro & $\begin{array}{l}\mathrm{IC}_{50}: 3.04 \pm 0.31 \\
\mathrm{mg} / \mathrm{ml}\end{array}$ & China & $\begin{array}{l}\text { H. pylori-urease in- } \\
\text { hibitory activity }\end{array}$ & (Li et al., 2016) \\
\hline 49. & Coptis deltoida & $\begin{array}{l}\text { Berberine along with } \\
\text { different alkaloids }\end{array}$ & & & $\begin{array}{l}\mathrm{IC}_{50}: 2.59 \pm 0.35 \\
\mathrm{mg} / \mathrm{ml}\end{array}$ & & $\begin{array}{l}\text { H. pylori-urease in- } \\
\text { hibitory activity }\end{array}$ & \\
\hline 50. & $\begin{array}{l}\text { Phellondendron } \\
\text { amurense } \\
\text { (Amur cork) }\end{array}$ & Berberine & Stem bark & In vitro & $\begin{array}{l}\mathrm{IC}_{50}: 85.11 \\
\pm 2.93 \mathrm{mg} / \mathrm{ml}\end{array}$ & China & $\begin{array}{l}\text { - H. pylori-urease in- } \\
\text { hibitory effect }\end{array}$ & (Li et al., 2016) \\
\hline 51. & $\begin{array}{l}\text { Phellondendron } \\
\text { chinense }\end{array}$ & & & & $\begin{array}{l}\mathrm{IC}_{50}: 61.14 \pm 2.55 \\
\mathrm{mg} / \mathrm{ml}\end{array}$ & & & \\
\hline 52. & $\begin{array}{l}\text { Calophyllum } \\
\text { brasiliense }\end{array}$ & $\begin{array}{l}\text { Brasiliensic, Isobrasiliensic } \\
\text { acids }\end{array}$ & Stem bark & In vitro & $\begin{array}{l}\text { MIC of } \\
\text { Brasiliensic acid: } \\
50 \mu \mathrm{g} / \mathrm{ml} \\
\text { Isobrasiliensic } \\
\text { acid: } 12.5 \mu \mathrm{g} / \mathrm{ml}\end{array}$ & Brazil & - Bacteriostatic effect & (Lemos et al., 2016) \\
\hline 53. & $\begin{array}{l}\text { Satureja } \\
\text { hortensis and } \\
\text { Origanum } \\
\text { vulgare subsp. } \\
\text { hirtum }\end{array}$ & $\begin{array}{l}\text { High content of phenols ( } 48 \text { - } \\
73 \% \text { ) with carvacrol }\end{array}$ & $\begin{array}{l}\text { Essential oil of } \\
2: 1 \mathrm{vol}\end{array}$ & In vitro & MIC: $0.5 \mu \mathrm{l} / \mathrm{ml}^{-1}$ & Serbia & $\begin{array}{l}\text { - Promising anti-H. py- } \\
\text { lori activity }\end{array}$ & $\begin{array}{l}\text { (Lesjak et al., } \\
\text { 2015) }\end{array}$ \\
\hline 54. & $\begin{array}{l}\text { Citrus bergamia } \\
\text { (Bergamot) }\end{array}$ & $\begin{array}{l}\text { Neohesperidin, Hesperetin } \\
\text { (aglycone), Neoeriocitrin, } \\
\text { Eriodictyol (aglycone), } \\
\text { Naringin Naringenin } \\
\text { (aglycone) }\end{array}$ & Fruits & In vitro & $\begin{array}{l}\text { MIC: } 0.625-5(\% \\
v / v)\end{array}$ & $\begin{array}{l}\text { Southern } \\
\text { Italy }\end{array}$ & $\begin{array}{l}\text { - Potent bacteriostatic } \\
\text { and synergistic effect } \\
\text { with antibiotics }\end{array}$ & $\begin{array}{l}\text { (Filocamo et al., } \\
\text { 2015) }\end{array}$ \\
\hline 55. & Crocus sativus L. & $\begin{array}{l}\text { Crocin and Safranal and semi- } \\
\text { synthetic derivative of } \\
\text { safranal }\end{array}$ & - & In vitro & $\begin{array}{l}\mathrm{MIC}_{50} \text { of safranal: } \\
32 \mu \mathrm{g} / \mathrm{ml}\end{array}$ & Italy & $\begin{array}{l}\text { Promising anti- } H \text {. } \\
\text { pylori effect }\end{array}$ & $\begin{array}{l}\text { (De Monte et al., } \\
\text { 2015) }\end{array}$ \\
\hline 56. & $\begin{array}{l}\text { Parthenium } \\
\text { hysterophorus } \\
\text { (Santa-Maria) }\end{array}$ & $\begin{array}{l}\text { Organic extract containing } \\
\text { dichloromethane }\end{array}$ & $\begin{array}{l}\text { Root and } \\
\text { aerial parts }\end{array}$ & In vitro & MIC: $15.6 \mu \mathrm{g} / \mathrm{ml}$ & Mexico & $\begin{array}{l}\text { Anti-H. pylori activity } \\
\text { by means of partial } \\
\text { urease inhibitory ac- } \\
\text { tivity and interfering } \\
\text { with bacterial motil- } \\
\text { ity and adherence }\end{array}$ & $\begin{array}{l}\text { (Espinosa-Rivero } \\
\text { et al., 2015) }\end{array}$ \\
\hline 57. & $\begin{array}{l}\text { Terminalia } \\
\text { catappa L. (Sea } \\
\text { almond) }\end{array}$ & $\begin{array}{l}\text { Phenolic compounds, } \\
\text { including Punicalagin, } \\
\text { Punicalin, Gallagic acid }\end{array}$ & Leaves & In vivo & MIC: $125.0 \mu \mathrm{g} / \mathrm{ml}$ & Brazil & $\begin{array}{l}\text { Significant gastropro- } \\
\text { tective and anti- } H \text {. } \\
\text { pylori effect }\end{array}$ & (Silva et al., 2015) \\
\hline 58. & $\begin{array}{l}\text { Lithrae } \\
\text { amolleoides } \\
\text { (Vell.) Engl. }\end{array}$ & $\begin{array}{l}\text { Catechol, Mannitol, Rutin, } \\
\text { Gallic acid, Ferulic acid and } \\
\text { Caffeic acid }\end{array}$ & Leaves & In vivo, In vitro & $\begin{array}{l}\text { MIC value for } \\
\text { catechol:0.5 } \mu \mathrm{g} / \\
\mathrm{ml}\end{array}$ & $\begin{array}{l}\text { South } \\
\text { America }\end{array}$ & $\begin{array}{l}\text { Potent anti-ulcero- } \\
\text { genic and anti-H. py- } \\
\text { lori effect }\end{array}$ & (Garro et al., 2015) \\
\hline 59. & $\begin{array}{l}\text { Maackia } \\
\text { amurensis }\end{array}$ & $\begin{array}{l}(-) \text { - Medicarpin, } \\
\text { Tectorigenin, Wistin }\end{array}$ & Stem bark & In vitro & $\begin{array}{l}(\mathrm{MIC})_{90} \text { of } \\
\text { medicarpin and } \\
\text { tectorigenin: } \\
25 \mu \mathrm{m} \text { and } \\
100 \mu \mathrm{m} \\
\text { respectively }\end{array}$ & Seoul & $\begin{array}{l}\text { - Potent anti-H. pylori } \\
\text { activity }\end{array}$ & (Park et al., 2015) \\
\hline 60. & $\begin{array}{l}\text { Hibiscus } \\
\text { sabdariffa } \mathrm{L} .\end{array}$ & Flavonoids, Anthocyanins & Calyces & In vitro & $\begin{array}{l}\text { MIC (alone): } \\
9.18-16.68 \mu \mathrm{g} / \\
\text { ml; } \sum \text { FIC with } \\
\text { CLA or MTZ: } \\
0.21-0.39\end{array}$ & - & $\begin{array}{l}\text { - Potent bacteriostatic } \\
\text { activity }\end{array}$ & $\begin{array}{l}\text { (Hassan et al., } \\
\text { 2015) }\end{array}$ \\
\hline 61. & Ruta graveolens & $\begin{array}{l}3 \text { (2”, 2“dimethyl butenyl) 3'- } \\
\text { hydroxydihydrofuropsoralen } \\
\text { and Arborinine alkaloid }\end{array}$ & - & In vitro & MIC: $\leq 2 \mathrm{mg} / \mathrm{ml}$ & - & $\begin{array}{l}\text { - Potent anti-H. pylori } \\
\text { activity }\end{array}$ & $\begin{array}{l}\text { (Osman et al., } \\
\text { 2015) }\end{array}$ \\
\hline 62. & $\begin{array}{l}\text { Zingiber } \\
\text { zerumbet (L.) } \\
\text { Smith (Bitter } \\
\text { ginger) }\end{array}$ & Zerumbone & Rhizome & In vivo, In vitro & MIC: $250 \mu \mathrm{g} / \mathrm{ml}$ & Malaysia & $\begin{array}{l}\text { - Potent gastroprotec- } \\
\text { tive } \\
\text { - Anti-secretory effect. } \\
\text { - Anti-H. pylori effect. }\end{array}$ & $\begin{array}{l}\text { (Sidahmed et al., } \\
\text { 2015) }\end{array}$ \\
\hline 63. & $\begin{array}{l}\text { Plantago ovata } \\
\text { (Blond plantain) }\end{array}$ & Apigenin, Luteolin, Baicalein & $\begin{array}{l}\text { Psyllium } \\
\text { (Husk) }\end{array}$ & Ex vivo & $\begin{array}{l}\text { IC against } H \text {. } \\
\text { pylori induced IL- } \\
8 \text { upregulation: } \\
5-10 \mu \mathrm{g} / \mathrm{ml}\end{array}$ & Pakistan & $\begin{array}{l}\text { Downregulates the } \\
\text { expression of IL-8 } \\
\text { and NFKB in gastric } \\
\text { epithelial cells in- } \\
\text { duced in response to } \\
\text { cagA-positive } H \text {. py- } \\
\text { lori }\end{array}$ & $\begin{array}{l}\text { (Yakoob et al., } \\
\text { 2015) }\end{array}$ \\
\hline 64. & $\begin{array}{l}\text { A combinatorial } \\
\text { extract }(1: 1) \text { of } \\
\text { Laminaria } \\
\text { japonica and } \\
\text { Oenothera } \\
\text { biennis }\end{array}$ & Fucoidan & $\begin{array}{l}\text { Whole plant of } \\
\text { L. Japonica and } \\
\text { seeds of } O \text {. } \\
\text { biennis }\end{array}$ & $\begin{array}{l}\text { In vivo (male } \\
\text { C57BL/6 } \\
\text { mice) } \\
\text { Clinical study }\end{array}$ & $\begin{array}{l}20,60,200 \mathrm{mg} / \\
\text { body weight/day } \\
\text { for } 2 \text { weeks } \\
\text { Capsules } \mathrm{f} 100 \text {, } \\
320,1000 \mathrm{mg} / \\
\text { person/day for } 8 \\
\text { weeks }\end{array}$ & Korea & $\begin{array}{l}\text { - Anti-bacterial and } \\
\text { eradicating effect on } \\
\text { H. pylori }\end{array}$ & (Kim et al., 2015) \\
\hline
\end{tabular}


Table 1 (Continued)

\begin{tabular}{|c|c|c|c|c|c|c|c|c|}
\hline No. & $\begin{array}{l}\text { Natural } \\
\text { Products }\end{array}$ & Active Compounds & Plant parts & Type of study & $\begin{array}{l}\text { Dose and } \\
\text { Duration }\end{array}$ & Country & $\begin{array}{l}\text { Findings of respective } \\
\text { study }\end{array}$ & References \\
\hline 65. & $\begin{array}{l}\text { Convolvulus } \\
\text { austro- } \\
\text { aegyptiacus }\end{array}$ & Scopoletin and Scopolin & Aerial parts & In vitro & MIC: $50 \mu \mathrm{g} / \mathrm{ml}$ & $\begin{array}{l}\text { Soudi } \\
\text { Arabia }\end{array}$ & $\begin{array}{l}\text { - Anti-H. pylori and } \\
\text { anti-ulcerogenic } \\
\text { activity }\end{array}$ & (Awaad et al., 2015) \\
\hline \multirow[t]{2}{*}{66.} & $\begin{array}{l}\text { Pistacia } \\
\text { lentiscus } \\
\text { (Mastic) }\end{array}$ & $\begin{array}{l}\alpha \text {-terpineol and (E)-Methyl } \\
\text { isoeugenol }\end{array}$ & $\begin{array}{l}\text { Essential oil of } \\
\text { mastic gum }\end{array}$ & In vitro & - & $\begin{array}{l}\text { Island } \\
\text { Hios of } \\
\text { Greece }\end{array}$ & $\begin{array}{l}\text { - Anti-bacterial effect } \\
\text { against CLR and MTZ } \\
\text { resistant } H \text {. pylori. }\end{array}$ & $\begin{array}{l}\text { (Miyamoto et al., } \\
\text { 2014) }\end{array}$ \\
\hline & & Isomasticadienolic acid & $\begin{array}{l}\text { Resin (Chios } \\
\text { mastic gum) }\end{array}$ & In vivo, In vitro & $\begin{array}{l}\text { MBC: } 0.202 \mathrm{mg} / \\
\mathrm{ml}\end{array}$ & Greece & $\begin{array}{l}\text { - Increased eradica- } \\
\text { tion of } H \text {. pylori } \\
\text { - No ameliorating } \\
\text { effect to H. pylori- } \\
\text { induced chronic gas- } \\
\text { tritis and inflamma- } \\
\text { tory manifestations }\end{array}$ & $\begin{array}{l}\text { (Paraschos et al., } \\
\text { 2007) }\end{array}$ \\
\hline 67. & $\begin{array}{l}\text { Anisomeles } \\
\text { indica (Catmint) }\end{array}$ & $\begin{array}{l}\text { Ovatodiolide (OVT), } \\
\text { Acteoside, Isoacteoside, and } \\
\text { Terniflorin }\end{array}$ & Whole plant & Ex vivo & $\begin{array}{l}\text { MBC: } 50-100 \mu \mathrm{m} \\
\text { depending on } H \text {. } \\
\text { pylori strains } \\
\text { IC against } \\
\text { invasion and } \\
\text { inflammatory } \\
\text { manifestations: } \\
\text { 15-60 } \mu \mathrm{m}\end{array}$ & Taiwan & $\begin{array}{l}\text { - Inhibitory effect on } \\
\text { bacterial adhesion to } \\
\text { AGS cells } \\
\text { - Downregulation of } H \text {. } \\
\text { pylori induced NFkB } \\
\text { and IL-8 expression } \\
\text { - Impairment of cyto- } \\
\text { toxin-associated } \\
\text { gene A (CagA) func- } \\
\text { tions by reduced } \\
\text { CagA translocation, } \\
\text { phosphorylation }\end{array}$ & (Rao et al., 2012) \\
\hline 68. & Garcinia fusca & $\begin{array}{l}\text { Fuscaxanthone I, } \\
\text { Cowaxanthone, and } \\
\text { Fukugiside }\end{array}$ & Root & In vitro & $\begin{array}{l}\text { MIC of } \\
\text { cowaxanthone: } \\
4.6 \mu \mathrm{m} \text {; MIC of } \\
\text { fukugiside: } \\
10.8 \mu \mathrm{m}\end{array}$ & - & $\begin{array}{l}\text { - Potent inhibitory ef- } \\
\text { fect on H. pylori }\end{array}$ & $\begin{array}{l}\text { (Nontakham et al., } \\
\text { 2014) }\end{array}$ \\
\hline 69. & $\begin{array}{l}\text { Magnolia } \\
\text { sieboldii } \\
\text { (Ovama } \\
\text { magnolia) }\end{array}$ & Dehydrocostus lactone & Leaves & In vitro & $\begin{array}{l}\text { MIC for H. pylori } \\
\text { ATCC } 700392: 4.9 \\
\text { mg/ml; MIC for } \\
\text { H. pylori ATCC } \\
700824 \text { strain: } \\
4.4 \mathrm{mg} / \mathrm{l}\end{array}$ & $\begin{array}{l}\text { South } \\
\text { Korea }\end{array}$ & $\begin{array}{l}\text { Potent bacteriostatic } \\
\text { and bactericidal ac- } \\
\text { tivity towards both } \\
\text { antibiotic-susceptible } \\
\text { and -resistant strains } \\
\text { of } H \text {. pylori }\end{array}$ & (Lee et al., 2014) \\
\hline 70. & $\begin{array}{l}\text { Ribes nigrum } \\
\text { (black currants) }\end{array}$ & Arabinogalactan protein & Seeds & $\begin{array}{l}\text { In vitro, Ex } \\
\text { vivo }\end{array}$ & - & $\begin{array}{l}\text { Northern } \\
\text { and } \\
\text { Central } \\
\text { Europe, } \\
\text { Asia, } \\
\text { North } \\
\text { America }\end{array}$ & $\begin{array}{l}\text { - Anti-adhesive effect } \\
\text { on } H \text {. pylori to stom- } \\
\text { ach cells by impairing } \\
\text { the binding of BabA } \\
\text { and fibronectin-bind- } \\
\text { ing adhesins to their } \\
\text { specific target mole- } \\
\text { cules }\end{array}$ & $\begin{array}{l}\text { (Messing et al., } \\
\text { 2014) }\end{array}$ \\
\hline 71. & $\begin{array}{l}\text { Geranium } \\
\text { wilfordii Maxim }\end{array}$ & $\begin{array}{l}\text { Corilagin and 1,2,3,6-tetra- } O \text { - } \\
\text { galloyl- } \beta \text {-D-glucose }\end{array}$ & Whole plant & In vitro & $\begin{array}{l}\text { MIC of corilagin: } \\
4 \mu \mathrm{g} / \mathrm{ml} \text {; MIC of } \\
\text { 1,2,3,6-tetra-O- } \\
\text { galloyl- } \beta \text {-D- } \\
\text { glucose: } 8 \mu \mathrm{g} / \mathrm{ml}\end{array}$ & China & $\begin{array}{l}\text { - Potent growth in- } \\
\text { hibitory effect }\end{array}$ & (Zhang et al., 2013) \\
\hline 72. & $\begin{array}{l}\text { Antrodia } \\
\text { camphorate } \\
\text { (medicinal } \\
\text { mushroom) }\end{array}$ & $\begin{array}{l}\text { Triterpenoid methylantcinate } \\
\text { B }\end{array}$ & Fruiting body & Ex vivo & $\mathrm{IC}_{50}: 50 \mu \mathrm{m}$ & China & $\begin{array}{l}\text { - Amelioration of } \mathrm{H} \text {. } \\
\text { pylori induced patho- } \\
\text { logic manifestation of } \\
\text { gastric epithelial cells } \\
\text { by inhibiting the } \\
\text { translocation and } \\
\text { phosphorylation of } \\
\text { CagA } \\
\text { - Blocking the activa- } \\
\text { tion of NF- } \kappa \text { B, p65 NF- } \\
\kappa \mathrm{B} \text { translocation and } \\
\text { IкB- } \alpha \text { phosphoryla- } \\
\text { tion }\end{array}$ & (Lin et al., 2013) \\
\hline 73. & $\begin{array}{l}\text { Lippia } \\
\text { integrifolia } \\
\text { (Gris.) } \\
\text { Hieronymus } \\
\text { (Verbenaceae) } \\
\text { (Incayuyo) }\end{array}$ & $\begin{array}{l}\text { Flavonoid hexosides, } \\
\text { Phenylethanoides (Acteoside, } \\
\text { Isoacteoside) and } \\
\text { Sesquiterpenes [(epi) } \\
\text { lippidulcine, } \\
\text { peroxylippidulcine] }\end{array}$ & Leaves & In vitro ex vivo & - & Argentina & $\begin{array}{l}\text { - Confers gastroprotec- } \\
\text { tion via its anti-ad- } \\
\text { hesive effect to } H \text {. } \\
\text { pylori }\end{array}$ & $\begin{array}{l}\text { (Marcial et al., } \\
\text { 2014) }\end{array}$ \\
\hline
\end{tabular}


Table 1 (Continued)

\begin{tabular}{|c|c|c|c|c|c|c|c|c|}
\hline No. & $\begin{array}{l}\text { Natural } \\
\text { Products }\end{array}$ & Active Compounds & Plant parts & Type of study & $\begin{array}{l}\text { Dose and } \\
\text { Duration }\end{array}$ & Country & $\begin{array}{l}\text { Findings of respective } \\
\text { study }\end{array}$ & References \\
\hline 74. & $\begin{array}{l}\text { Withania } \\
\text { somnifera } \\
\text { (Rennet) }\end{array}$ & Withaferin A & - & Ex vivo & - & - & $\begin{array}{l}\text { - Downregulates the } \\
\text { expression of IL-8 and } \\
\text { NF-kB activation in } H \text {. } \\
\text { pylori infected gastric } \\
\text { epithelial cells. } \\
\text { - No bactericidal activ- } \\
\text { ity, } \\
\text { - Preventive against } \\
\text { inflammatory mani- } \\
\text { festations triggered } \\
\text { by } H \text {. pylori. }\end{array}$ & (Kim et al., 2016) \\
\hline 75. & $\begin{array}{l}\text { Garcinia } \\
\text { mangostana } \\
\text { (Purple } \\
\text { mangosteen) }\end{array}$ & $\alpha$-Mangostin & $\begin{array}{l}\text { Pericarp of } \\
\text { fruits }\end{array}$ & $\begin{array}{l}\text { In vitro } \\
\text { Ex vivo } \\
\text { In vivo }\end{array}$ & $\begin{array}{l}\text { MIC: } 31.3 \mu \mathrm{g} / \mathrm{ml} \\
- \\
300 \mathrm{mg} / \mathrm{kg} \text { body } \\
\text { weight for } 3 \text { days }\end{array}$ & Thailand & $\begin{array}{l}\text { - Nano-encapsulated } \\
\text { extract exerts anti- } H \text {. } \\
\text { pylori activity } \\
\text { - Blocks binding of } H \text {. } \\
\text { pylori to gastric epi- } \\
\text { thelial cells }\end{array}$ & $\begin{array}{l}\text { (Pan-In et al., } \\
2014)\end{array}$ \\
\hline 76. & $\begin{array}{l}\text { Raphano } \\
\text { brassica } \\
\text { (intergeneric } \\
\text { hybrid of the } \\
\text { genera } \\
\text { Raphanus } \\
\text { (radish) and } \\
\text { Brassica } \\
\text { (cabbages) }\end{array}$ & $\begin{array}{l}\text { Glucoraphanin and } \\
\text { Glucoraphenin }\end{array}$ & Whole plants & $\begin{array}{l}\text { In vivo } \\
\text { (Mongolian } \\
\text { gerbils) }\end{array}$ & $\begin{array}{l}2 \% \text { extract for } 10 \\
\text { weeks }\end{array}$ & Japan & $\begin{array}{l}\text { - Amelioration of } H \text {. } \\
\text { pylori-induced gas- } \\
\text { tric inflammatory } \\
\text { manifestations }\end{array}$ & $\begin{array}{l}\text { (Yamada et al., } \\
\text { 2014) }\end{array}$ \\
\hline 77. & $\begin{array}{l}\text { Inula viscose }(\mathrm{L}) \\
\text { Ait (Asteraceae) }\end{array}$ & Sesquiterpenes, Lactones & Leaves & In vitro & $\begin{array}{l}\text { MIC: } 83 \mu \mathrm{g} / \mathrm{ml} \\
\text { MBC: } 104 \mu \mathrm{g} / \mathrm{ml}\end{array}$ & Jordan & $\begin{array}{l}\text { - Strong anti-H. pylori } \\
\text { effect }\end{array}$ & $\begin{array}{l}\text { (Masadeh et al., } \\
\text { 2014) }\end{array}$ \\
\hline 78. & $\begin{array}{l}\text { Aloysia triphylla } \\
\text { (L'Her.) Britton } \\
\text { (Verbenaceae) }\end{array}$ & $\begin{array}{l}\text { Verbascosides and Luteolin- } \\
\text { 7-diglucuronide }\end{array}$ & Leaves & In vitro & $\begin{array}{l}\text { MIC: } 90 \mu \mathrm{g} / \mathrm{ml} \\
\text { MBC: } 125 \mu \mathrm{g} / \mathrm{ml}\end{array}$ & Jordan & $\begin{array}{l}\text { - Strong anti-H. pylori } \\
\text { effect }\end{array}$ & \\
\hline 79. & $\begin{array}{l}\text { Impatiens } \\
\text { balsamina } \mathrm{L}\end{array}$ & $\begin{array}{l}\text { 2-Methoxy-1,4- } \\
\text { naphthoquinone }\end{array}$ & Whole plants & Ex vivo & $\begin{array}{l}\text { IC50: } 24.01 \\
\pm 0.38 \mu \mathrm{m} \text { upon } \\
\text { an incubation } \\
\text { period of } 48 \mathrm{~h}\end{array}$ & Taiwan & $\begin{array}{l}\text { - Strong anti-H. pylori } \\
\text { activity } \\
\text { - Promising candidate } \\
\text { in the therapeutic } \\
\text { management of } H \text {. } \\
\text { pylori-caused gastric } \\
\text { adenocarcinoma }\end{array}$ & $\begin{array}{l}\text { (Wang and Lin, } \\
\text { 2012) }\end{array}$ \\
\hline 80. & $\begin{array}{l}\text { Cuphea } \\
\text { aequipetala }\end{array}$ & Flavonoids, Tannins & Aerial parts & In vitro & MIC: $125 \mu \mathrm{g} / \mathrm{ml}$ & Mexico & - Anti-H. pylori activity & $\begin{array}{l}\text { (Palacios-Espinosa } \\
\text { et al., 2014) }\end{array}$ \\
\hline 81. & $\begin{array}{l}\text { Satureja } \\
\text { bachtiarica } \\
\text { (Bunge) }\end{array}$ & $\begin{array}{l}\text { Carvacrol, Thymol, p-Cymene } \\
\text { and } \gamma \text {-Terpinene }\end{array}$ & Essential oil & In vitro & $\begin{array}{l}\text { MIC: } 0.035 \\
\pm 0.13 \mu \mathrm{l} / \mathrm{ml}\end{array}$ & Iran & $\begin{array}{l}\text { - Anti H. pylori activity, } \\
\text { may be exploited as } \\
\text { therapeutic candi- } \\
\text { date. }\end{array}$ & (Falsafi et al., 2015) \\
\hline 82. & $\begin{array}{l}\text { Cyrtocara } \\
\text { procera Kunth } \\
\text { (Chupandilla) }\end{array}$ & Sterols & Bark & In vitro & $\begin{array}{l}\text { MIC: } 17.8-125 \\
\mu \mathrm{g} / \mathrm{ml}\end{array}$ & Mexico & - Bacteriostatic effect & $\begin{array}{l}\text { (Escobedo- } \\
\text { Hinojosa et al., } \\
\text { 2012) }\end{array}$ \\
\hline 83. & $\begin{array}{l}\text { Pyrus communis } \\
\text { (Bartlett and } \\
\text { Starkrimson } \\
\text { pear) }\end{array}$ & Catechin, Quercetin & Pulp & In vitro & - & USA & $\begin{array}{l}\text { - Growth inhibitory ef- } \\
\text { fect on } H \text {. pylori }\end{array}$ & (Sarkar et al., 2015) \\
\hline 84. & $\begin{array}{l}\text { Emblica } \\
\text { officialis }\end{array}$ & Phenolic compounds & Fruit & In vitro & MIC: $100 \mu \mathrm{g} / \mathrm{ml}$ & India & - Anti-H. pylori activity & $\begin{array}{l}\text { (Franklin et al., } \\
\text { 2012) }\end{array}$ \\
\hline 85. & Piper carpunya & $\begin{array}{l}\text { Vitexin, Isovitexin, } \\
\text { Rhamnopyranolvitexin } \\
\text { Isoembigenin, Neolignan, } \\
\text { which is a DNA polymerase } \beta \\
\text { lyase inhibitor, and (6S, 9S)- } \\
\text { Roseoside, }\end{array}$ & Leaves & In vitro, In vivo & MIC: $6.25 \mu \mathrm{g} / \mathrm{ml}$ & $\begin{array}{l}\text { South } \\
\text { America }\end{array}$ & $\begin{array}{l}\text { - Anti-H. pylori effect } \\
\text { - Gastroprotective ef- } \\
\text { fect } \\
\text { - Inhibitory effect on } \\
\text { gastric microsomal } \\
\mathrm{H}^{+}, \mathrm{K}^{+} \text {-ATPase. }\end{array}$ & (Quílez et al., 2010) \\
\hline 86. & $\begin{array}{l}\text { Feijoa } \\
\text { sellowiana }\end{array}$ & Flavone & Fruit & In vitro & - & Italy & $\begin{array}{l}\text { - Potent anti-H. pylori } \\
\text { effect }\end{array}$ & (Basile et al., 2010) \\
\hline 87. & $\begin{array}{l}\text { Juglans nigra } \\
\text { (Eastern black } \\
\text { walnut) }\end{array}$ & $\begin{array}{l}\text { Juglone (5- hydroxy-1,4- } \\
\text { naphthoquinone) }\end{array}$ & $\begin{array}{l}\text { Leaves, unripe } \\
\text { hulls of fruits }\end{array}$ & In vitro & $\begin{array}{l}\mathrm{IC}_{50} \text { against } \\
\text { HpCGS: } 7.0 \\
\pm 0.7 \mu \mathrm{mol} / \mathrm{l} \\
\text { HpFabB: } 20 \\
\pm 1 \mu \mathrm{mol} / \mathrm{l} \\
\mathrm{HpFabZ:} 30 \\
\pm 4 \mu \mathrm{mol} / \mathrm{l}\end{array}$ & - & $\begin{array}{l}\text { - Inhibits three impor- } \\
\text { tant enzymes of } H \text {. } \\
\text { pylori } \\
\text { - Cystathionine } \\
\gamma \text {-synthase (HpCGS) } \\
\text { (noncompetitively) } \\
\text { - Malonyl-CoA:acyl } \\
\text { carrier protein }\end{array}$ & (Kong et al., 2008) \\
\hline
\end{tabular}


Table 1 (Continued)

\begin{tabular}{|c|c|c|c|c|c|c|c|c|}
\hline No. & $\begin{array}{l}\text { Natural } \\
\text { Products }\end{array}$ & Active Compounds & Plant parts & Type of study & $\begin{array}{l}\text { Dose and } \\
\text { Duration }\end{array}$ & Country & $\begin{array}{l}\text { Findings of respective } \\
\text { study }\end{array}$ & References \\
\hline & & & & & & & $\begin{array}{l}\text { transacylase } \\
\text { (HpFabD) (uncompe- } \\
\text { titively) } \\
\text { - } \text { B-Hydroxyacyl-ACP } \\
\text { dehydratase (HpFabZ) } \\
\text { (competitively) }\end{array}$ & \\
\hline 88. & $\begin{array}{l}\text { Mallotus } \\
\text { philippinensis } \\
\text { (Kamala tree) }\end{array}$ & Rottlerin & Fruits & In vitro & $\begin{array}{l}\text { MBC: } 3.12-6.25 \\
\mathrm{mg} / \mathrm{l}\end{array}$ & Pakistan & $\begin{array}{l}\text { - strong bactericidal } \\
\text { effect against clari- } \\
\text { thromycin and met- } \\
\text { ronidazole resistant } \\
\text { H. pylori strains }\end{array}$ & (Zaidi et al., 2009b) \\
\hline 89. & $\begin{array}{l}\text { Prunus mume } \\
\text { (Japanese } \\
\text { apricot) }\end{array}$ & $(+)$ - Syringaresinol & Fruits & In vitro & $\begin{array}{l}\mathrm{IC}_{50} \text { against } \\
\text { bacterial } \\
\text { motility: } 50 \mu \mathrm{g} / \\
\text { ml }\end{array}$ & Japan & $\begin{array}{l}\text { - Inhibits motility of } H \text {. } \\
\text { pylori }\end{array}$ & $\begin{array}{l}\text { (Miyazawa et al., } \\
\text { 2006) }\end{array}$ \\
\hline 90. & $\begin{array}{l}\text { Artemisia } \\
\text { douglasiana } \\
\text { Besser }\end{array}$ & Dehydroleucodine & Aerial parts & In vitro & MIC: $1-8$ mg/l & Argentina & $\begin{array}{l}\text { - Anti-H. pylori activity } \\
\text { - May be a potential } \\
\text { therapeutic candidate } \\
\text { against CLR and MTZ } \\
\text { resistant strains }\end{array}$ & (Vega et al., 2009) \\
\hline 91. & Rheum emodi & Anthraquinones & Rhizomes & In vivo & $\begin{array}{l}3.0 \mathrm{mg} / \mathrm{ml} \text { orally } \\
\text { for } 7 \text { days } \\
\text { (minimal dose } \\
\text { for eradication) }\end{array}$ & India & & \\
\hline 92. & $\begin{array}{l}\text { Curcuma amada } \\
\text { (Mango ginger) }\end{array}$ & $\begin{array}{l}\text { Caffeic acid, Gallic acid, } \\
\text { Ferulic acid, Syringic acid, p- } \\
\text { Coumaric acid, Cinnamic } \\
\text { acid, Gentisic acid }\end{array}$ & Rhizome & In vitro & $\begin{array}{l}\text { MIC of free } \\
\text { phenolic and } \\
\text { bound phenolics } \\
\text { extract: } 64 \pm 6.1 \\
\mu \mathrm{g} / \mathrm{ml} \text {, and } 38 \\
\pm 2.2 \mu \mathrm{g} / \mathrm{ml} \\
\text { respectively }\end{array}$ & India & $\begin{array}{l}\text { Exerts anti-H. pylori } \\
\text { activity by impairing } \\
\text { the function of } \mathrm{H}^{+} \text {, } \\
\mathrm{K}^{+} \text {- ATPase pump } \\
\text { required for ATP } \\
\text { synthesis in bacteria } \\
\text { - Inhibiting } H \text {. pylori- } \\
\text { urease }\end{array}$ & $\begin{array}{l}\text { (Siddaraju and } \\
\text { Dharmesh, 2007) }\end{array}$ \\
\hline
\end{tabular}

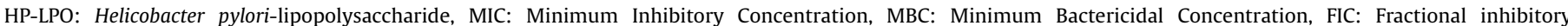
concentration.

$\mathrm{IC}_{50}$ : the concentration at which any selective parameter is reduced to $50 \%$ of the control group.

MTZ: Metronidazole, CLR: Clarithromycin, AMX: Amoxicillin.

components such as CAPE, quercetin, and hesperidin) strongly inhibit the replication of peripheral blood mononuclear cells and $\mathrm{T}$ lymphocytes separated from the peripheral blood by modulating the Erk signal pathway. CAPE has an inhibitory effect on NFkBdependent transcriptional activity without affecting the degradation of the cytoplasmic NFkB inhibitory protein IB-kB. CAPE can inhibit both the DNA-binding and transcriptional activity of nuclear factor of activated T cells (NFAT) (Márquez et al., 2004). Propolis also upregulates the synthesis of TGF- $\beta 1$ (transforming growth factor $\beta 1$ ) via T-regulatory cells. Thus, propolis exerts antiinflammatory and immunosuppressive effects (Ansorge et al., 2003).

The VacA of $H$. pylori causes acute inflammation of the gastric mucosa associated with infiltration of mast cells. Infiltrating mast cells release different proinflammatory cytokines and chemoattractants, including PAF, IL-8, LTB4, TNF $\alpha$, and GM-CSF (granulocyte-monocyte colony stimulating factor) and lead to neutrophil infiltration and inflammatory manifestations (Fig. 1). The mast cells, which are first-line defence of the host, may also contribute to the pathogenesis caused by H. pylori (Supajatura et al., 2002) and act as effector cells in this regard (Nakajima et al., 1997).

Basophilic cells (bone-derived mast cells) produce different polyamines such as putrescine and spermine. Spermidine is an important component of secretory granules. It is required for their maturation and functions after transformation. These also act as paracrine signals for the growth and proliferation of epithelial, tumour and bacterial cells. Mast cells synthesize these polyamines from ornithine by ornithine decarboxylase (ODC) (Fajardo et al., 2001; García-Faroldi et al., 2010). In addition to NADPH oxidase, different protein tyrosine kinases play critical roles in the degranulation and release of the chemo attractant factors mentioned above (Inoue et al., 2008; Min and Shin, 2009; Schmidt et al., 2009). It has been shown that propolis has an inhibitory effect on myeloperoxidase activity, NADPH-oxidase (Frenkel et al., 1993), ODC, and tyrosine protein kinase in guinea pig mast cells (Miyataka et al., 1997). Thus, propolis acts on several enzymatic thresholds to compromise the survival, activation and function of mast cells, thus indirectly inhibiting neutrophil infiltration and other inflammatory manifestations.

Artepillin C, a major component of Brazilian propolis, exerts an anti-inflammatory effect by inhibiting prostaglandin $\mathrm{E}_{2}$ and nitric oxide (NO) through NFkB modulation (Paulino et al., 2008). Different endotoxins such as Hp-NAP (Satin et al., 2000) and formylated peptides (f-methionylleucylphenylalanine) secreted from $H$. pylori can act as chemotactic factors for granulocytes, causing increased membrane permeability of the luminal propia and neutrophil infiltration associated with the release of ROS and protease (Grisham and Granger, 1988). An ethanolic extract of propolis exerts its anti-inflammatory effect and accelerates regenerative activity by inhibiting ROS production by neutrophils. In addition, CAPE, galangin, kaempferol, and kaempferoid of propolis may also participate in the protective mechanism (Fig. 1) (Krol et al., 1996). 


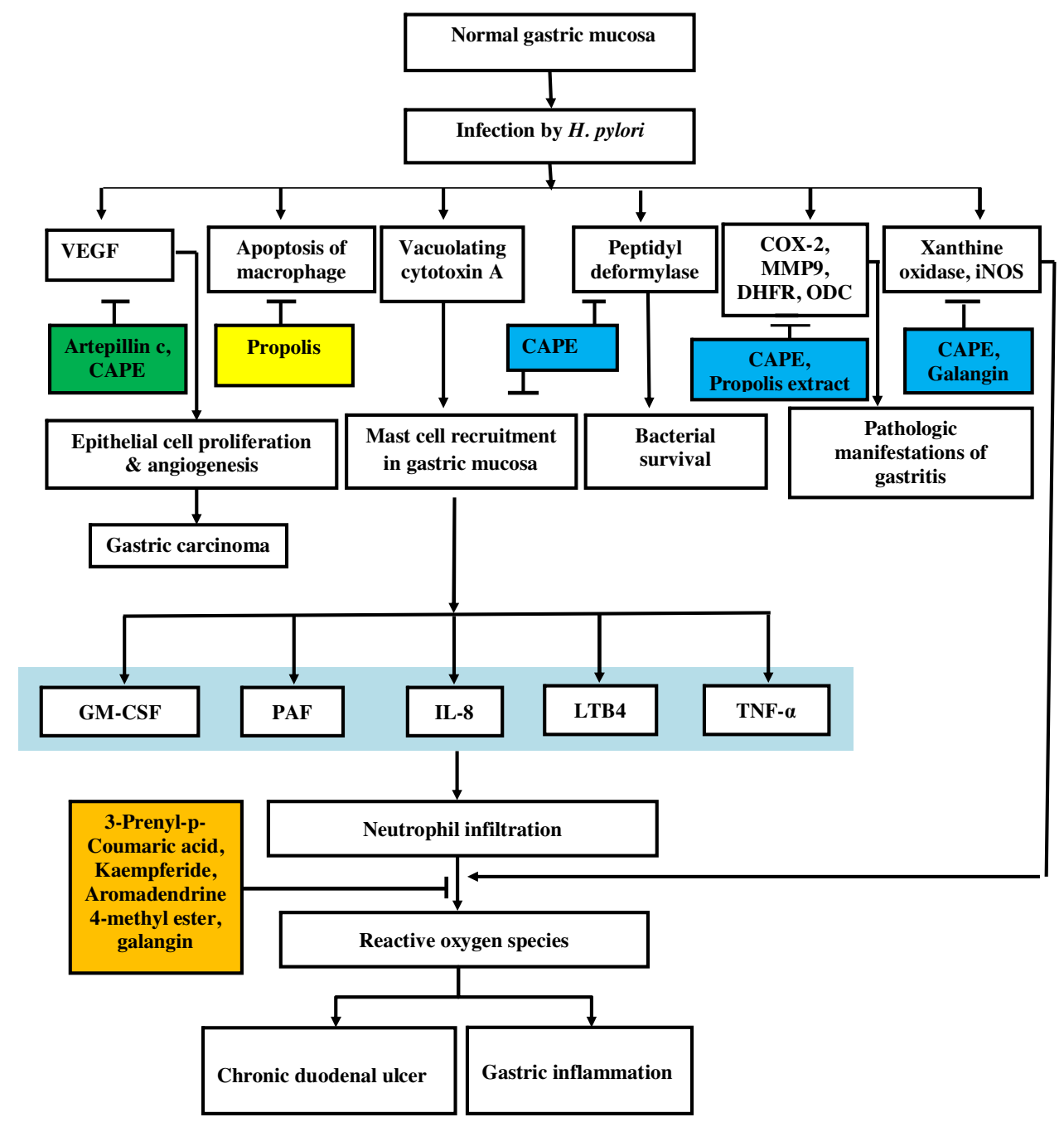

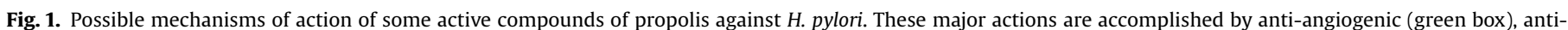

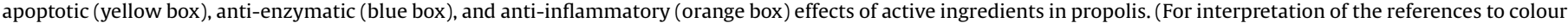
in this figure legend, the reader is referred to the web version of this article.)

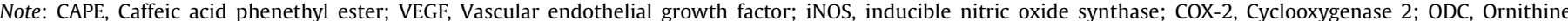

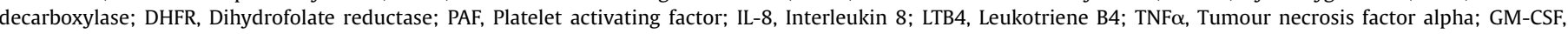
Granulocyte monocyte colony stimulating factor

Increased IL-8 production by mononuclear cells and $H$. pyloriinfected mucosal cells is also an important pathological manifestation in $H$. pylori-associated gastritis. $H$. pylori-LPS mediates MAPK signalling and AP1 and NFkB activation at the promoter level of the IL-8 gene (Bhattacharyya et al., 2002; Huang et al., 1995). The NFKB transcription factor upregulates the expression of the IL- 8 gene (Sharma et al., 1998). CAPE blocks the activation and cytokine- and mitogen-induced expression of NFкB and AP1 (Abdel-Latif et al., 2005; Natarajan et al., 1996). In an in vitro study, it was shown that incubation of a human gastric adenocarcinoma cell line with an ethanolic extract of propolis significantly decreased IL-8 production in a dose-dependent fashion and thus ameliorated inflammatory manifestations (Skiba et al., 2011).

Heat shock protein 60 (Hp-HSP60) and urease produced by $H$. pylori are potent triggers of both IL-6 synthesis and release from macrophages of human mucosa (Gobert et al., 2004; Harris et al., 1998). The mRNA level of IL- 6 and the degree of $H$. pylori-associated chronic gastritis are positively correlated (Azadegan-Dehkordi et al., 2015). IL-6 in combination with TGF- $\beta$ triggers the differentiation of naive CD4+ T-cells into Th17 cells. Moreover, IL- 6 blocks the development of regulatory T-cells mediated by TGF- $\beta$ (Kimura and Kishimoto, 2010; Korn et al., 2009). An imbalance in the level of Th17/Treg leads to the development of autoimmune and chronic inflammatory manifestations (Kao et al., 2010; Miyara et al., 2011). Propolis and its constituents inhibit the synthesis of IL6 by peritoneal macrophages of mice (Bachiega et al., 2012), emphasizing its potential to be used in $H$. pylori-mediated gastric cancers.

Attenuation of $\mathrm{H}$. pylori-mediated gastrointestinal diseases via inhibition of essential enzymes

Peptide deformylase (PDF) is an important key enzyme for bacterial survival and pathogenesis. It is a divalent metalloproteinase (requiring cobalt) which removes the $\mathrm{N}$-formyl group of $\mathrm{N}$ terminal methionine from nascent proteins to make them functionally active (Mazel et al., 1994). CAPE serves as a potent competitive inhibitor of PDF (Fig. 1). It blocks the binding of substrate to the active site of PDF while exerting no effect on metal ion binding or on different metal-dependent catalytic processes of host tissues (Cui et al., 2013).

Baltas et al. (2016) showed in an in vitro study that ethanolic extracts of propolis containing different phenolic compounds 
significantly inhibit $H$. pylori urease at inhibition concentrations ranging from 0.260 to $1.525 \mathrm{mg} / \mathrm{ml}$.

H. pylori infection causes increased DNA damage (the presence of 8 OH-dG adducts) in gastric epithelial cells by inducing increased oxidative stress (Baik et al., 1996). The survival of such damaged cells is an important factor that determines a person's health (Smoot et al., 2000). An increased level of cyclo-oxygenase2 (COX-2) expression by $H$. pylori accelerates the progression of gastric cancer cells (increased cancer invasion and angiogenesis) via TLR2 and TLR9 (Chang et al., 2005). In gastric malignant cells, $H$. pylori causes increased expression of the genes encoding IL-8, urokinase type plasminogen activator (uPA) and MMP9, a vascular endothelial growth factor (Kitadai et al., 2003). Ethanolic extract of Brazilian propolis (specifically the compound artepillin C) has been confirmed to have an anti-angiogenic effect by inhibiting the proliferation of endothelial cells (Fig. 1) (Ahn et al., 2007). Artepillin C and CAPE significantly downregulate the expression of vascular endothelial growth factor (VEGF) and MMPs expressed by different cells (Fig. 1) (Keshavarz et al., 2009). CAPE and Chinese red propolis possess a very potent suppressive effect against the VEGF-mediated proliferation and migration of human umbilical vein endothelial cells (HUVECs) (Izuta et al., 2009). CAPE also suppresses the expression of the gene encoding COX-2 (Fig. 1) (Michaluart et al., 1999) and the expression as well as the activity of MMP9 by acting on NFkB in malignant hepatic cells (Fig. 1) (Jin et al., 2005; Lee et al., 2008).

In another in vitro study, a water extract of propolis has shown an inhibitory effect on dihydrofolate reductase (Fig. 1).This is an important enzyme in DNA metabolism, playing a crucial role in the rapid cell proliferation that occurs during bacterial and tumour cell growth (Strehl et al., 1994). Therefore, propolis may have a protective effect on $H$. pylori-associated gastric carcinoma.

ODC is the rate-limiting enzyme in the biosynthesis of polyamines (especially spermine), which play crucial roles in proliferation and differentiation of cells and the entrance of cells from quiescent (G0) to the G1 phase and the initiation of DNA replication (Heby, 1981; Krokan and Eriksen, 1977; Mamont et al., 1976). L-arginine enters either in the L-arginase or NO synthase (NOS) pathway. NO synthesized by iNOS (inducible-NOS) can affect $H$. pylori because in order to survive, $H$. pylori attenuates the NOS pathway by making L-arginine unavailable to iNOS, directing arginine to an alternative pathway by self-inducing arginase and host macrophage arginase II and ODC. The generation of spermine by ODC inhibits iNOS translation, while NO mediates $H$. pylori killing. The oxidation of spermine by spermine oxidase produces hydrogen peroxide, which exerts oxidative stress causing apoptosis of macrophages and polarization of mitochondrial membrane potential and DNA damage in gastric epithelial cells (Chaturvedi et al., 2012). There is a positive correlation between the ODC mRNA expression and $H$. pylori-associated increased risk of gastric cancer (Konturek et al., 2003). Different compounds in propolis, such as methyl caffeate, phenylethylcaffeate, and phenylethyl dimethyl caffeate, block the activity of ODC (Fig. 1) and subsequently, protein tyrosine kinase and the synthesis of DNA, RNA, and protein in HT 29 adenocarcinoma cells (Rao et al., 1992).

Propolis may have a similar chemoprotective effect on gastric epithelial cells. Both inflammatory and normal epithelial cells express the iNOS gene, and the production of NO exerts a carcinogenic effect in chronic inflammation (Chen et al., 2006). Ethanolic extracts of propolis and CAPE inhibit iNOS gene expression by the suppression of NFkB activation and the catalytic activity of iNOS (Song et al., 2002).
Attenuation of $\mathrm{H}$. pylori-mediated gastrointestinal diseases via antioxidant effects

Xanthine oxidase is one of the major sources of oxygen-derived free radicals (ODRF) in all eukaryotic cells. The oxygen radicals are an important component of the respiration burst but also cause tissue damage and inflammation. Xanthine oxidase-derived ODRF contributes to $H$. pylori-associated gastro duodenal inflammation and chronic duodenal ulcer (Ben-Hamida et al., 1998; Halliwell and Gutteridge, 2015). In vitro studies have shown that a propolis extract (containing CAPE, galangin) has an inhibitory effect on xanthine oxidase (Fig. 1). In addition, propolis also has an antilipoperoxidative effect (Liu et al., 2002; Russo et al., 2002). Neutrophils also produce ROS and cause oxidative stress (Kanashiro et al., 2004). The different components of Brazilian green propolis, such as kaempferide, aromadendrine $4^{\prime}$-methyl-ester, and 3-prenyl-p coumaric acid, all have been reported to play inhibitory roles in the production of ROS by activated neutrophils (Fig. 1) (Simões et al., 2004). It has been shown that Turkish propolis inhibits DNA damage induced by hydrogen peroxide in cultured fibroblasts (Aliyazicioglu et al., 2011). Propolis can also inhibit the apoptosis of macrophages by affecting glutathione (GSH) and the TNF/NFKB signalling pathways (Fig. 1) (Claus et al., 2000; Pascual et al., 1994).

In another study, propolis from Portugal has been reported to confer protection on the plasma membrane of erythrocytes from oxidative stress induced by 2-2'-azobis-(2-amidinopropane) dihydrochloride (APPH), a strong source of free radicals. The propolis also has higher antioxidant properties than green tea. Propolis contain flavonoids associated with antioxidative functions in a variety of ways, such as hydrogen donors, reducing agents, chelating metal ions, and neutralizing singlet oxygen (Cao et al., 1997; Rice-Evans et al., 1996). Therefore, propolis prevents oxidative stress by protecting cellular macromolecules and maintaining the integrity of cellular structure and function (Valente et al., 2011). However, Coelho et al. (2007), in a pilot study of $H$. pylori-infected females $(n=11)$ and males $(n=7)$, have shown that Brazilian green propolis has minimal therapeutic effects, which underscores the demand of applying propolis in clinical trials.

\section{Future perspectives and conclusions}

The challenge of $H$. pylori resistance to antibiotics is on the rise, constituting a major global public health problem. Since many conventional treatments still fail to achieve complete eradication of $H$. pylori with a high risk of developing microbial resistance, natural products are useful alternatives either as a main-stream treatment or as an adjuvant. Nevertheless, although a promising number of studies involved in the identification, characterization and extraction of natural products having antimicrobial chemicals exist, more extensive and sophisticated investigations are required to accelerate the pace towards new nutraceutical drug development. This may include determination of the pharmacokinetics, pharmacodynamics, therapeutic safety window, toxicity and synergistic activities of the constituents.

Based on the evidence presented in this review, it is clear that propolis exerts its protective effect against different gastrointestinal tract diseases induced by $H$. pylori by functioning on the host physiology as well as on the bacterial physiology at different enzymatic and immunological cascade reaction steps. Therefore, it can be concluded that propolis may be used as a useful alternative agent to antibiotics in the treatment of $H$. pylori-related gastrointestinal diseases. 
Conflict of interest

The authors declare that there is no conflict of interest regarding the publication of this paper.

\section{Acknowledgements}

We would like to acknowledge University Sains Malaysia (USM) Vice-Chancellor Award (2015/2016) and USM Global Fellowship (2014/2015) awarded to Md. Asiful Islam and Fahmida Alam, respectively, to pursue their PhD degrees. We also acknowledge the Research University Grant (RUT) (1001/PPSP/853005) for providing some financial support.

\section{References}

Abbas, Z., Yakoob, J., Abid, S., Jafri, W., Islam, M., Azam, Z., et al., 2009. Furazolidone, co-amoxiclav, colloidal bismuth subcitrate, and esomeprazole for patients who failed to eradicate Helicobacter pylori with triple therapy. Dig. Dis. Sci. 54, 19531957.

Abdel-Latif, M.M., Windle, H.J., Homasany, E.L.B.S., Sabra, K., Kelleher, D., 2005. Caffeic acid phenethyl ester modulates Helicobacter pylori-induced nuclear factor-kappa B and activator protein-1 expression in gastric epithelial cells. Br. J. Pharmacol. 146, 1139-1147.

Ahn, M-R. Kunimasa, K., Ohta, T. Kumazawa, S, Kamihira, M., Kaji, K., et al 2007. Suppression of tumour-induced angiogenesis by Brazilian propolis: major component artepillin C inhibits in vitro tube formation and endothelial cell proliferation. Cancer Lett. 252, 235-243.

Akagi, T., Motegi, M., Tamura, A., Suzuki, R., Hosokawa, Y., Suzuki, H., et al., 1999. A novel gene, MALT1 at 18q21, is involved in $\mathrm{t}(11 ; 18)(\mathrm{q} 21$; q21) found in lowgrade B-cell lymphoma of mucosa-associated lymphoid tissue. Oncogene 18 5785-5794.

Aliyazicioglu, Y., Demir, S., Turan, I., Cakiroglu, T., Akalin, I., Deger, O., et al., 2011 Preventive and protective effects of Turkish propolis on $\mathrm{H}_{2} \mathrm{O}_{2}$-induced DNA damage in foreskin fibroblast cell lines. Acta Biol. Hung. 62, 388-396.

Allison, C.C., Kufer, T.A., Kremmer, E., Kaparakis, M., Ferrero, R.L., 2009. Helicobacter pylori induces MAPK phosphorylation and AP-1 activation via a NOD1dependent mechanism. J. Immunol. 183, 8099-8109.

Amieva, M.R., Vogelmann, Covacci, R., Tompkins, A., Nelson, L.S., Falkow, W.J.S. 2003. Disruption of the epithelial apical-junctional complex by Helicobacte pylori CagA. Science 300, 1430-1434.

Amin, M., Anwar, F., Naz, F., Mehmood, T., Saari, N., 2013. Anti-Helicobacter pylori an urease inhibition activities of some traditional medicinal plants. Molecules 18 2135-2149.

Ansorge, S., Reinhold, D., Lendeckel, U., 2003. Propolis and some of its constituents down-regulate DNA synthesis and inflammatory cytokine production but induce TGF- $\beta 1$ production of human immune cells. Zeitschrift für Naturforschung C 58, 580-589.

Awaad, A.S., Al-Rifai, A.A., El-Meligy, R.M., Alafeefy, A.M., Zain, M.E. 2015. New activities for isolated compounds from convolvulus austro-aegyptiacus as antiulcerogenic, Anti-Helicobacter pylori and their mimic synthesis using bioguided fractionation. Phytother. Res. 29, 1311-1316.

Ayala, G., Escobedo-Hinojosa, W.L., De La Cruz-Herrera, C.F, Romero, I., 2014. Exploring alternative treatments for Helicobacter pylori infection. World J. Gastroenterol. 20, 1450-1469.

Azadegan-Dehkordi, F., Bagheri, N., Shirzad, M., Sanei, M.H., HashemzadehChaleshtori, M., Rafieian-Kopaei, M., et al., 2015. Correlation between mucosa IL-6 mRNA expression level and virulence factors of Helicobacter pylori in Iranian adult patients with chronic gastritis. Jundishapur J. Microbiol. 8 (8), e21701.

Bachiega, T.F., Orsatti, C.L., Pagliarone, A.C., Sforcin, J.M., 2012. The effects of propolis and its isolated compounds on cytokine production by murine macrophages. Phytother. Res. 26, 1308-1313.

Bae, M., Jang, S., Lim, J.W., Kang, J., Bak, E.J., Cha, J.-H., et al., 2014. Protective effect of Korean Red Ginseng extract against Helicobacter pylori-induced gastric inflammation in Mongolian gerbils. J. Ginseng Res. 38, 8-15.

Baik, S.-C., Youn, H.-S., Chung, M.-H., Lee, W.-K., Cho, M.-J., Ko, G.-H., et al., 1996. Increased oxidative DNA damage in Helicobacter pylori-infected human gastric mucosa. Cancer Res. 56, 1279-1282.

Baltas, N., Karaoglu, S.A., Tarakci, C., Kolayli, S., 2016. Effect of propolis in gastric disorders: inhibition studies on the growth of Helicobacter pylori and production of its urease. J. Enzyme Inhib. Med. Chem. 31 (Supp. 2), 1-5.

Banskota, A., Tezuka, Y., Adnyana, I., Ishii, E., Midorikawa, K., Matsushige, K., et al., 2001. Hepatoprotective and anti-Helicobacter pylori activities of constituents from Brazilian propolis. Phytomedicine 8, 16-23.

Basile, A., Conte, B., Rigano, D., Senatore, F., Sorbo, S., 2010. Antibacterial and antifungal properties of acetonic extract of Feijoa sellowiana fruits and its effect on Helicobacter pylori growth. J. Med. Food 13, 189-195.

Beales, I., Calam, J., 1998. Interleukin $1 \beta$ and tumour necrosis factor $\alpha$ inhibit acid secretion in cultured rabbit parietal cells by multiple pathways. Gut 42, 227
Beek, D., De Craen, A., 1999. A systematic review of Helicobacter pylori eradication therapy -the impact of antimicrobial resistance on eradication rates. Aliment. Pharmacol. Ther. 13, 1047-1055.

Beigier-Bompadre, M., Moos, V., Belogolova, E., Allers, K., Schneider, T., Churin, Y., et al., 2011. Modulation of the CD4+ T-cell response by Helicobacter pylori depends on known virulence factors and bacterial cholesterol and cholesterol $\alpha$-glucoside content. J. Infect. Dis. 204, 1339-1348.

Ben-Hamida, A., Man, W., McNeil, N., Spencer, J., 1998. Histamine, xanthine oxidase generated oxygen-derived free radicals and Helicobacter pylori in gastroduodenal inflammation and ulceration. Inflamm. Res. 47, 193-199.

Bhattacharjee, M., Bhattacharjee, S., Gupta, A., Banerjee, R.K., 2002. Critical role of an endogenous gastric peroxidase in controlling oxidative damage in H. pylori-mediated and nonmediated gastric ulcer. Free Radic. Biol. Med. 32 731-743.

Bhattacharyya, A., Pathak, S., Datta, S., Chattopadhyay, S., Joyoti, B., Kundu, M., 2002. Mitogen-activated protein kinases and nuclear factor- $\mathrm{B}$ regulate Helicobacter pylori-mediated interleukin-8 release from macrophages. Biochem. J 368, 121129.

Blaser, M.J., Atherton, J.C., 2004. Helicobacter pylori persistence: biology and disease. J. Clin. Invest. 113, 321-333.

Bodger, K., Crabtree, J.E., 1998. Helicobacter pylori and gastric inflammation. Br. Med. Bull. 54, 139-150.

Bonifácio, B.V., Dos Santos Ramos, M.A., Da Silva, P.B., Bauab, T.M., 2014 Antimicrobial activity of natural products against Helicobacter pylori: a review. Ann. Clin. Microbiol. Antimicrob. 13, 54.

Bonvehí, J.S., Gutiérrez, A.L., 2012. The antimicrobial effects of propolis collected in different regions in the Basque Country (Northern Spain). World J. Microbiol. Biotechnol. 28, 1351-1358.

Borrelli, F., Izzo, A.A., 2000. The plant kingdom as a source of anti-ulcer remedies. Phytother. Res. 14, 581-591.

Borrelli, F., Maffia, P., Pinto, L., Ianaro, A., Russo, A., Capasso, F., et al., 2002. Phytochemical compounds involved in the anti-inflammatory effect of propolis extract. Fitoterapia 73, S53-S63.

Boyanova, L., Derejian, S., Koumanova, R., Katsarov, N., Gergova, G., Mitov, I., et al., 2003. Inhibition of Helicobacter pylori growth in vitro by Bulgarian propolis: preliminary report. J. Med. Microbiol. 52, 417-419.

Boyanova, L., Gergova, G., Nikolov, R., Derejian, S., Lazarova, E., Katsarov, N., et al., 2005. Activity of Bulgarian propolis against 94 Helicobacter pylori strains in vitro by agar-well diffusion, agar dilution and disc diffusion methods. J. Med. Microbiol. 54, 481-483.

Brown, J.C., Jiang, X.-P., 2013. Activities of muscadine grape skin and polyphenolic constituents against Helicobacter pylori. J. Appl. Microbiol. 114, 982-991.

Calvet, X., Garcia, N., Lopez, T., Gisbert, J., Gene, E., Roque, M., 2000. A meta-analysis of short versus long therapy with a proton pump inhibitor, clarithromycin and either metronidazole or amoxycillin for treating Helicobacter pylori infection. Aliment. Pharmacol. Ther. 14, 603-610.

Cao, G., Sofic, E., Prior, R.L., 1997. Antioxidant and prooxidant behaviour of flavonoids: structure-activity relationships. Free Radic. Biol. Med. 22 749-760.

Cao, D. Jiang, J., You, L., Jia, Z., Tsukamoto, T., Cai, H., et al., 2016. The protective effects of $18 \beta$-glycyrrhetinic acid on Helicobacter pylori-infected gastric mucosa in Mongolian Gerbils. BioMed Res. Int. 2016 doi:http://dx.doi.org/10.1155/2016/ 4943793.

Castro, M., Romero, C., DE Castro, A., Vargas, J., Medina, E., Millan, R., et al., 2012. Assessment of Helicobacter pylori eradication by virgin olive oil. Helicobacter 17, 305-311.

Chandrashekar, K.B., Dharmesh, S.M., 2016. Gastro protective and H+, K+-ATPase/H. pylori inhibitory properties of pectic polysaccharides from potato. Int. J. Biol. Macromol. 84, 385-393.

Chang, Y.-J., Wu, M.-S., Lin, J.-T., Chen, C.-C., 2005. Helicobacter pylori-induced invasion and angiogenesis of gastric cells is mediated by cyclooxygenase- 2 induction through TLR2/TLR9 and promoter regulation. J. Immunol. 175, $8242-$ 8252.

Chaturvedi, R., De Sablet, T., Coburn, L.A., Gobert, A.P., Wilson, K.T., 2012. Arginine and polyamines in Helicobacter pylori-induced immune dysregulation and gastric carcinogenesis. Amino Acids. 42, 627-640.

Chen, C.N., Hsieh, F.J., Cheng, Y.M., Chang, K.J., Lee, P.H., 2006. Expression of inducible nitric oxide synthase and cyclooxygenase-2 in angiogenesis and clinical outcome of human gastric cancer. J. Surg. Oncol. 94, 226-233.

Chey, W.D., Wong, B.C., 2007. American College of Gastroenterology guideline on the management of Helicobacter pylori infection. Am. J. Gastroenterol. 102, 1808 1825.

Churin, Y., Al-Ghoul, L., Kepp, O., Meyer, T.F., Birchmeier, W., Naumann, M., 2003. Helicobacter pylori CagA protein targets the c-Met receptor and enhances the motogenic response. J. Cell Biol. 161, 249-255.

Cindoruk, M., Erkan, G., Karakan, T., Dursun, A., Unal, S., 2007. Efficacy and safety of Saccharomyces boulardii in the 14-day triple anti-Helicobacter pylori therapy: a prospective randomized placebo-controlled double-blind study. Helicobacter $12,309-316$

Claus, R., Kinscherf, R., Gehrke, C., Bonaterra, G., Basnet, P., Metz, J., et al., 2000 Antiapoptotic effects of propolis extract and propol on human macrophages exposed to minimally modified low density lipoprotein. Arzneimittelforschung 50, 373-379.

Coelho, L., Bastos, E., Resende, C.C., Sanches, B., De Castro, F., Moretzsohn, L., et al. 2007. Brazilian green propolis on Helicobacter pylori infection. a pilot clinical study. Helicobacter 12, 572-574. 
Conteduca, V., Sansonno, D., Lauletta, G., Russi, S., Ingravallo, G., Dammacco, F., 2013. H. pylori infection and gastric cancer: state of the art (review). Int. J. Oncol. 42, $5-18$.

Correa, P., Houghton, J., 2007. Carcinogenesis of Helicobacter pylori. Gastroenterology 133, 659-672.

Covacci, A., Telford, J.L., Del Gludice, G., Parsonnet, J., Rappuoli, R., 1999. Helicobacter pylori virulence and genetic geography. Science 284, 1328-1333.

Cover, T.L., Dooley, C., Blaser, M., 1990. Characterization of and human serologic response to proteins in Helicobacter pylori broth culture supernatants with vacuolizing cytotoxin activity. Infect. Immun. 58, 603-610.

Cremonini, F., Di Caro, S., Covino, M., Armuzzi, A., Gabrielli, M., Santarelli, L., et al., 2002. Effect of different probiotic preparations on anti-Helicobacter pylori therapy-related side effects: a parallel group, triple blind, placebo-controlled study. Am. J. Gastroenterol. 97, 2744-2749.

Cui, K., Lu, W., Zhu, L., Shen, X., Huang, J., 2013. Caffeic acid phenethyl ester (CAPE), an active component of propolis, inhibits Helicobacter pylori peptide deformylase activity. Biochem. Biophys. Res. Commun. 435, 289-294.

Day, A.S., Jones, N.L., Lynett, J.T., Jennings, H.A., Fallone, C.A., Beech, R., et al., 2000. cagE is a virulence factor associated with Helicobacter pylori-induced duodenal ulceration in children. J. Infect. Dis. 181, 1370-1375.

De Monte, C., Bizzarri, B., Gidaro, M.C., Carradori, S., Mollica, A., Luisi, G., et al., 2015. Bioactive compounds of Crocus sativus L. and their semi-synthetic derivatives as promising anti-Helicobacter pylori, anti-malarial and anti-leishmanial agents. J. Enzyme Inhib. Med. Chem. 30, 1027-1033.

De, R., Kundu, P., Swarnakar, S., Ramamurthy, T., Chowdhury, A., Nair, G.B., et al., 2009. Antimicrobial activity of curcumin against Helicobacter pylori isolates from India and during infections in mice. Antimicrob. Agents Chemother. 53, 1592-1597.

Denizot, Y., Sobhani, I., Rambaud, J., Lewin, M., Thomas, Y., Benveniste, J., 1990. Pafacether synthesis by Helicobacter pylori. Gut 31, 1242-1245.

Dierlamm, J., Baens, M., Wlodarska, I., Stefanova-Ouzounova, M., Hernandez, J.M., Hossfeld, D.K., et al., 1999. The apoptosis inhibitor gene API2 and a novel 18q gene MLT, are recurrently rearranged in the $\mathrm{t}(11 ; 18)(\mathrm{q} 21 ; \mathrm{q} 21)$ associated with mucosa-associated lymphoid tissue lymphomas. Blood 93, 3601-3609.

Dinarello, C.A., 1984. Interleukin-1 and the pathogenesis of the acute-phase response. New Engl. J. Med. 311, 1413-1418.

Duck, W.M., Sobel, J., Pruckler, J.M., Song, Q., Swerdlow, D., Friedman, C., et al., 2004. Antimicrobial resistance incidence and risk factors among Helicobacter pyloriinfected persons. United States.Emerg Infect Dis. 10, 1088-1094.

Eaton, K.A., Mefford, M., Thevenot, T., 2001. The role of T cell subsets and cytokines in the pathogenesis of Helicobacter pylori gastritis in mice. J. Immunol. 166, 74567461.

Eck, M., Schmausser, B., Scheller, K., Toksoy, A., Kraus, M., Menzel, T., et al., 2000. CXC chemokines Groo/IL-8 and IP-10/MIG in Helicobacter pylori gastritis. Clin. Exp. Immunol. 122, 192-199.

Escobedo-Hinojosa, W.I., Del Carpio, J.D., Palacios-Espinosa, J.F., Romero, I., 2012. Contribution to the ethnopharmacological and anti-Helicobacter pylori knowledge of Cyrtocarpa procera Kunth (Anacardiaceae). J. Ethnopharmacol. 143, 363-371.

Espinosa-Rivero, J., Rendón-Huerta, E., Romero, I., 2015. Inhibition of Helicobacter pylori growth and its colonization factors by Parthenium hysterophorus extracts. J. Ethnopharmacol. 174, 253-260.

Eyoum Bille, B., Nguepi, E., 2016. In vitro and In vivo anti-Helicobacter activities of Eryngium foetidum (Apiaceae) Bidens pilosa (Asteraceae), and Galinsoga ciliata (Asteraceae) against Helicobacter pylori. BioMed. Res. Int. 2016, 1-7. doi:http:// dx.doi.org/10.1155/2016/2171032.

Fahey, J.W., Stephenson, K.K., Wallace, A.J., 2015. Dietary amelioration of Helicobacter infection. Nutr. Res. 35, 461-473.

Fajardo, I., Urdiales, J.L., Paz, J.C., Chavarría, T., Sánchez-Jiménez, F., Medina, M.A., 2001. Histamine prevents polyamine accumulation in mouse C57. 1 mast cell cultures. Eur. J. Biochem. 268, 768-773.

Falsafi, T., Moradi, P., Mahboubi, M., Rahimi, E., Momtaz, H., Hamedi, B., 2015. Chemical composition and anti-Helicobacter pylori effect of Satureja bachtiarica Bunge essential oil. Phytomedicine 22, 173-177.

Falush, D., Kraft, C., Taylor, N.S., Correa, P., Fox, J.G., Achtman, M., et al., 2001. Recombination and mutation during long-term gastric colonization by Helicobacter pylori: estimates of clock rates, recombination size, and minimal age. Proc. Natl. Acad. Sci. 98, 15056-15061.

Filocamo, A., Bisignano, C., Ferlazzo, N., Cirmi, S., Mandalari, G., Navarra, M., 2015. In vitro effect of bergamot (Citrus bergamia) juice against cagA-positive andnegative clinical isolates of Helicobacter pylori. BMC Complem. Altern. Med. 15 256.

Franklin, A., Rao, U., Vijayakumar, R., Srikumar, R., 2012. In vitro anti-Helicobacter pylori activity of Emblica officinalis. Int. J. Microbiol. Res. 3, 216-220.

Frenkel, K., Wei, H., Bhimani, R., Ye, J., Zadunaisky, J.A., Huang, M.-T., et al., 1993. Inhibition of tumour promoter-mediated processes in mouse skin and bovine lens by caffeic acid phenethyl ester. Cancer Res. 53, 1255-1261.

Fukuda, T., Kimura, S., Arakawa, T., Kobayashi, K., 1990. Possible role of leukotrienes in gastritis associated with Campylobacter pylori. J. Clin. Gastroenterol.12, S131-S134.

Galmiche, A., Rassow, J., Doye, A., Cagnol, S., Chambard, J.C., Contamin, S., et al., 2000. The N-terminal $34 \mathrm{kDa}$ fragment of Helicobacter pylori vacuolating cytotoxin targets mitochondria and induces cytochrome c release. EMBO J. 19, 6361-6370.

Gao, X.-Z., Qiao, X.-L., Song, W.-C., Wang, X.-F., Liu, F., 2010. Standard triple, bismuth pectin quadruple and sequential therapies for Helicobacter pylori eradication. World J. Gastroenterol. 16, 4357-4362.
García-Faroldi, G., Rodríguez, C.E., Urdiales, J.L., Pérez-Pomares, J.M., Dávila, J.C., Pejler, G., et al., 2010. Polyamines are present in mast cell secretory granules and are important for granule homeostasis. PLoS One 5, e15071.

Garro, M.F., Ibáñez, A.G.S., Vega, A.E., Sosa, A.C.A., Pelzer, L., Saad, J.R., et al., 2015 Gastroprotective effects and antimicrobial activity of Lithraea molleoides and isolated compounds against Helicobacter pylori. J. Ethnopharmacol. 176, 469474.

Gatta, L., Vakil, N., Vaira, D., Scarpignato, C., 2013. Global eradication rates for Helicobacter pylori infection: systematic review and meta-analysis of sequential therapy. BMJ 347, f4587.

Gisbert, J.P., Calvet, X., O'connor, A., Mégraud, F., O'morain, C.A., 2010. Sequential therapy for Helicobacter pylori eradication: a critical review. J. Clin. Gastroenterol. 44, 313-325.

Gobert, A.P., Bambou, J.-C., Werts, C., Balloy, V., Chignard, M., Moran, A.P., et al., 2004 Helicobacter pylori heat shock protein 60 mediates interleukin-6 production by macrophages via a toll-like receptor (TLR)-2-, TLR-4-, and myeloid differentiation factor 88-independent mechanism. J. Biol. Chem. 279, 245-250.

Gomez-Flores, R., Espinosa-Ramos, D., Quintanilla-Licea, R., Barrón-Gonzalez, M.P., Tamez-Guerra, P., Tamez-Guerra, R., et al., 2016. Antimicrobial activity of Gymnosperma glutinosum (spreng.) Less. (asteraceae) methanol extracts against Helicobacter pylori. Afr. J. Tradit. Compl. Altern. Med. 13 (4), 55-59.

Göõz, M., Göõz, P., Smolka, A.J., 2001. Epithelial and bacterial metalloproteinases and their inhibitors in H. pylori infection of human gastric cells. Am. J. Physiol. Gastrointest. Liver Physiol. 281 (3), G823-G832.

Graham, D.Y., Shiotani, A., 2008. New concepts of resistance in the treatment of Helicobacter pylori infections. Nat. Clin. Practice Gastroenterol. Hepatol. 5, 321 331.

Greiner, A., Marx, A., Heesemann, J., Leebmann, J., Schmausser, B., MüllerHermelink, H., 1994. Idiotype identity in a MALT-type lymphoma and B cells in Helicobacter pylori associated chronic gastritis. Lab. Invest. 70, 572-578.

Grisham, M.B., Granger, D.N., 1988. The chemotactic peptide N-formyl methionylleucyl-phenylalanine increases mucosal permeability in the distal ileum of the rat. Gastroenterology 95, 651-656.

Halliwell, B., Gutteridge, J.M., 2015. Free Radicals in Biology and Medicine. Oxford University Press, USA.

Han, J.H., Khin, P.P., Sohn, U.D., 2016. Effect of Rumex quaticus herba extract against Helicobacter pylori-induced inflammation in gastric epithelial cells. J. Med. Food 19, 31-37.

Harris, P.R., Ernst, P.B., Kawabata, S, Kiyono, H., Graham, M.F. Smith, P.D., 1998 Recombinant Helicobacter pylori urease activates primary mucosal macrophages. J. Infect. Dis. 178, 1516-1520.

Hassan, S.T., Berchová, K., Majerová, M., Pokorná, M., Švajdlenka, E., 2015. In vitro synergistic effect of Hibiscus sabdariffa aqueous extract in combination with standard antibiotics against Helicobacter pylori clinical isolates. Pharm. Biol. 54 (9), 1736-1740.

Hatakeyama, M., 2004. Oncogenic mechanisms of the Helicobacter pylori CagA protein. Nat. Rev. Cancer 4, 688-694.

Heby, O., 1981. Role of polyamines in the control of cell proliferation and differentiation. Differentiation 19, 1-20.

Higashi, H., Tsutsumi, R., Muto, S., Sugiyama, T., Azuma, T., Asaka, M., et al., 2002 SHP-2 tyrosine phosphatase as an intracellular target of Helicobacter pylori CagA protein. Science 295, 683-686.

Higashi, K., De Castro, S., 1994. Propolis extracts are effective against Trypanosoma cruzi and have an impact on its interaction with host cells. J. Ethnopharmacol. 43, 149-155.

Hommes, D., Jansen, J., Smit, F., Zhao, Y., Fockens, P., Tytgal, G., 1992. Enhanced production of interleukin-8 in ulcerative colitis. Gastroenterology 102, A927.

Honjo, T., Kinoshita, K., Muramatsu, M., 2002. Molecular mechanism of class switch recombination: linkage with somatic hypermutation. Annu. Rev. Immunol. 20, 165-196.

Hopkins, R.J., Girardi, L.S., Turney, E.A., 1996. Relationship between Helicobacter pylori eradication and reduced duodenal and gastric ulcer recurrence: a review. Gastroenterology 110, 1244-1252.

Hosokawa, Y., Suzuki, H., Suzuki, Y., Takahashi, R., Seto, M., 2004. Antiapoptotic function of apoptosis inhibitor 2-MALT1 fusion protein involved in $\mathrm{t}(11 ; 18)$ (q21; q21) mucosa-associated lymphoid tissue lymphoma. Cancer Res. 64, 3452-3457.

Huang, H.-L., Ko, C.-H., Yan, Y.-Y., Wang, C.-K., 2014. Anti-adhesion and antiinflammation effects of noni (Morinda citrifolia) fruit extracts on AGS cells during Helicobacter pylori infection. J. Agric. Food Chem. 62, 2374-2383.

Huang, J., O’Toole, P.W., Doig, P., 1995. Stimulation of interleukin-8 production in epithelial cell lines by Helicobacter pylori. Infect. Immun. 63, 1732-1738.

Hurduc, V., Plesca, D., Dragomir, D., Sajin, M., Vandenplas, Y., 2009. A randomized, open trial evaluating the effect of Saccharomyces boulardii on the eradication rate of Helicobacter pylori infection in children. Acta Paediatr. 98, 127-131.

Inoue, T., Suzuki, Y., Yoshimaru, T., Ra, C., 2008. Reactive oxygen species produced up-or downstream of calcium influx regulate proinflammatory mediator release from mast cells: role of NADPH oxidase and mitochondria. Biochim. Biophys. Acta (BBA)-Mol. Cell Res. 1783, 789-802.

International Agency for Research on Cancer (IARC), 1994. Anonymous live flukes and Helicobacter pylori. IARC Working group on the evaluation of carcinogenic risks to humans, Lyon, 7-14 June 1994. IARC Monogr. Eval. Carcinog. Risks Hum. $61,1-241$.

Izuta, H., Shimazawa, M., Tsuruma, K., Araki, Y., Mishima, S., Hara, H., 2009. Bee products prevent VEGF-induced angiogenesis in human umbilical vein endothelial cells. BMC Complement. Altern. Med. 9, 45. 
Jin, U.-H., Chung, T.-W., Kang, S.-K., Suh, S.-J., Kim, J.-K., Chung, K.-H., et al., 2005. Caffeic acid phenyl ester in propolis is a strong inhibitor of matrix metalloproteinase-9 and invasion inhibitor: isolation and identification. Clin. Chim. Acta 362, 57-64.

Jo, B.-S., Cho, Y.-J., 2016. Inhibitory activity against Helicobacter pylori of isolated compounds from Pinus koraiensis Siebold et Zucc Leaves. J. Appl. Biol. Chem. 59 (1), 19-23.

Jüttner, S., Cramer, T., Wessler, S., Walduck, A., Gao, F., Schmitz, F., et al., 2003. Helicobacter pylori stimulates host cyclooxygenase-2 gene transcription: critical importance of MEK/ERK-dependent activation of USF1/-2 and CREB transcription factors. Cell. Microbiol. 5, 821-834.

Kanashiro, A., Kabeya, L., Polizello, A., Lopes, N., Lopes, J., Lucisano-Valim, Y., 2004 Inhibitory activity of flavonoids from Lychnophora sp. on generation of reactive oxygen species by neutrophils upon stimulation by immune complexes. Phytother. Res. 18, 61-65.

Kanbur, M., Eraslan, G., Silici, S., 2009. Antioxidant effect of propolis against exposure to propetamphos in rats. Ecotoxicol. Environ. Saf. 72, 909-915.

Kao, J.Y., Zhang, M., Miller, M.J., Mills, J.C., Wang, B., Liu, M., et al., 2010. Helicobacter pylori immune escape is mediated by dendritic cell-induced Treg skewing and Th17 suppression in mice. Gastroenterology 138, 1046-1054.

Keates, S., Keates, A.C., Warny, M., Peek, R.M., Murray, P.G., Kelly, C.P., 1999. Differential activation of mitogen-activated protein kinases in AGS gastric epithelial cells by cag+ and cag- Helicobacter pylori. J. Immunol. 163, 5552-5559.

Keates, S., Sougioultzis, S., Keates, A.C., Zhao, D., Peek, R.M., Shaw, L.M., et al., 2001. cag+ Helicobacter pylori induce transactivation of the epidermal growth factor receptor in AGS gastric epithelial cells. J. Biol. Chem. 276, 48127-48134.

Kehrer, J.P., 2008. Free radicals as mediators of tissue injury and disease. Crit. Rev. Toxicol. 23 (1), 21-48.

Keshavarz, M., Mostafaie, A., Mansouri, K., Shakiba, Y., Motlagh, H.R.M., 2009. Inhibition of corneal neovascularization with propolis extract. Arch. Med. Res. 40, 59-61.

Kim, G. Kim, T.H., Kang, M.J. Choi, JA, Pack, D.Y, Lee, I.R, et al, 2016. Inhibitory effect of Withaferin A on Helicobacter pylori-induced IL-8 production and NF- $\mathrm{B}$ activation in gastric epithelial cells. Mol. Med. Rep. 13, 967-972.

Kim, J.J., Tao, H., Carloni, E., Leung, W.K., Graham, D.Y., Sepulveda, A.R., 2002. Helicobacter pylori impairs DNA mismatch repair in gastric epithelial cells. Gastroenterology 123, 542-553.

Kim, J.M., 2016. H. pylori virulence factors: toxins (CagA, VacA, DupA, OipA, IceA). In Kim, N. (Ed.), Helicobacter Pylori. Springer, Singapore, pp. 77-88.

Kim, T.-S., Shin, K., Jeon, J.H., Choi, E.-K., Choi, Y., Lee, S.-P., et al., 2015. Comparative analysis of anti-Helicobacter pylori activities of FEMY-R7 composed of Laminaria japonica and Oenothera biennis extracts in mice and humans. Lab. Animal Res. 31, 7-12.

Kimura, A., Kishimoto, T., 2010. IL-6: regulator of Treg/Th17 balance. Eur. J. Immunol. 40, 1830-1835.

Kitadai, Y, Sasaki, A., Ito, M., Tanaka, S, Oue, N., Yasui, W., et al, 2003. Helicobacter pylori infection influences expression of genes related to angiogenesis and invasion in human gastric carcinoma cells. Biochem. Biophys. Res. Commun. $311,809-814$.

Kong, Y.-H., Zhang, L., Yang, Z.-Y., Han, C., Hu, L.-H., Jiang, H.-L., et al., 2008. Natura product juglone targets three key enzymes from Helicobacter pylori: inhibition assay with crystal structure characterization. Acta Pharmacol. Sin. 29, 870.

Konturek, P.C., Konturek, S.J., Sito, E., Kwiecien, N., Obtulowicz, W., Bielanski, W. Hahn, E.G., 2001. Luminal N $\alpha$-methyl histamine stimulates gastric acid secretion in duodenal ulcer patients via releasing gastrin. Eur. J. Pharmacol. 412 (2), 181-185.

Konturek, P.C., Rembiasz, K., Konturek, S.J., Stachura, J., Bielanski, W., Galuschka, K. et al., 2003. Gene expression of ornithine decarboxylase, cyclooxygenase-2, and gastrin in atrophic gastric mucosa infected with Helicobacter pylori before and after eradication therapy. Dig. Dis. Sci. 48, 36-46.

Korn, T., Bettelli, E., Oukka, M., Kuchroo, V.K., 2009. IL-17 and th17 cells. Annu. Rev. Immunol. 27, 485-517.

Krokan, H., Eriksen, A., 1977. DNA synthesis in HeLa cells and isolated nuclei after treatment with an inhibitor of spermidine synthesis, methyl glyoxal bis (guanylhydrazone). Eur. J. Biochem. 72, 501-508.

Krol, W., Scheller, S., Czuba, Z., Matsuno, T., Zydowicz, G., Shani, J., et al., 1996. Inhibition of neutrophils' chemiluminescence by ethanol extract of propolis (EEP) and its phenolic components. J. Ethnopharmacol. 55, 19-25.

Kujumgiev, A., Tsvetkova, I., Serkedjieva, Y., Bankova, V., Christov, R., Popov, S., 1999 Antibacterial, antifungal and antiviral activity of propolis of differen geographic origin. J. Ethnopharmacol. 64, 235-240.

Kuo, C.-H., Weng, B.-C., Wu, C.-C., Yang, S.-F., Wu, D.-C., Wang, Y.-C., 2014. Apigenin has anti-atrophic gastritis and anti-gastric cancer progression effects in Helicobacter pylori-infected Mongolian gerbils. J. Ethnopharmacol. 151, 10311039.

Kusters, J.G., Van Vliet, A.H., Kuipers, E.J., 2006. Pathogenesis of Helicobacter pylor infection. Clin. Microbiol. Rev. 19, 449-490.

Lai, C.-H., Fang, S.-H., Rao, Y.K., Geethangili, M., Tang, C.-H., Lin, Y.-J., et al., 2008. Inhibition of Helicobacter pylori-induced inflammation in human gastric epithelial AGS cells by Phyllanthus urinaria extracts. J. Ethnopharmacol. 118, $522-526$.

Langton, S., Cesareo, S., 1992. Helicobacter pylori associated phospholipase A2 activity: a factor in peptic ulcer production? J. Clin. Pathol. 45, 221-224

Lee, H.-K., Song, H.E., Lee, H.-B., Kim, C.-S., Koketsu, M., Ngan, L.T.M., et al., 2014 Growth inhibitory, bactericidal, and morphostructural effects of dehydrocostus lactone from Magnolia sieboldii Leaves on antibiotic-susceptible and-resistant strains of Helicobacter pylori. PLoS One 9, e95530.

Lee, K.W., Kang, N.J., Kim, J.H., Lee, K.M., Lee, D.E., Hur, H.J., et al., 2008. Caffeic acid phenethyl ester inhibits invasion and expression of matrix metalloproteinase in SK-Hep1 human hepatocellular carcinoma cells by targeting nuclear factor kappa B. Genes \& Nutrition. 2, 319-322.

Lemos, L.M., Oliveira, R.B., Sampaio, B.L., Ccana-Ccapatinta, G.V., Da Costa, F.B. Martins, D.T., 2016. Brasiliensic and isobrasiliensic acids: isolation from Calophyllum brasiliense Cambess: and anti-Helicobacter pylori activity. Nat. Prod. Res. 30 (23), 2720-2725.

Lengsfeld, C., Titgemeyer, F., Faller, G., Hensel, A., 2004. Glycosylated compounds from okra inhibit adhesion of Helicobacter pylori to human gastric mucosa. J. Agric. Food Chem. 52, 1495-1503.

Lesjak, M., Simin, N., Orcic, D., Franciskovic, M., Knezevic, P., Beara, I., et al., 2015 Binary and tertiary mixtures of Satureja hortensis and Origanum vulgare essential oils as potent antimicrobial agents against Helicobacter pylori. Phytother. Res. 30 (3), 476-484.

Li, C., Xie, J., Chen, X., Mo, Z., Wu, W., Liang, Y., et al., 2016. Comparison of Helicobacter pylori urease inhibition by Rhizoma Coptidis, Cortex Phellodendri and Berberine: mechanisms of interaction with the sulfhydryl group. Planta Med. 82, 305-311.

Lin, C.-J., Rao, Y.K., Hung, C.-L., Feng, C.-L., Lane, H.-Y., Tzeng, D.T., et al., 2013. Inhibition of Helicobacter pylori CagA-induced pathogenesis by methylantcinate B from Antrodia camphorata. Evid. Based Complem. Altern. Med. doi:http://dx. doi.org/10.1155/2013/682418.

Liu, C.-F., Lin, C.-C., Lin, M.-H., Lin, Y.-S., Lin, S.-C., 2002. Cytoprotection by propolis ethanol extract of acute absolute ethanol-induced gastric mucosal lesions. Am. J. Chin. Med. 30, 245-254.

Liu, J.-H., Li, L., Shang, X.-D., Zhang, J.-L., Tan, Q., 2016. Anti-Helicobacter pylori activity of bioactive components isolated from Hericium erinaceus. J. Ethnopharmacol. 183, 54-58.

Lu, C., Sang, J., He, H., Wan, X., Lin, Y., Li, L., Li, Y., Yu, C., 2016. Probiotic supplementation does not improve eradication rate of Helicobacter pylori infection compared to placebo based on standard therapy: a meta-analysis. Sci. Rep. 6, 23522. doi:http://dx.doi.org/10.1038/srep23522.

Lu, H., HSu, P.-I., Graham, D.Y., Yamaoka, Y., 2005. Duodenal ulcer promoting gene of Helicobacter pylori. Gastroenterology 128, 833-848.

Machado, A.M.D., Figueiredo, C., Touati, E., Máximo, V., Sousa, S., Michel, V., et al., 2009. Helicobacter pylori infection induces genetic instability of nuclear and mitochondrial DNA in gastric cells. Clin. Cancer Res. 15, 2995-3002.

Mai, U., Perez-Perez, G., Wahl, L., Wahl, S., Blaser, M., Smith, P., 1991. Soluble surface proteins from Helicobacter pylori activate monocytes/macrophages by lipopolysaccharide-independent mechanism. J. Clin. Invest. 87, 894.

Malfertheiner, P., Megraud, F., O’Morain, C., Bazzoli, F., El-Omar, E., Graham, D., et al., 2007. Current concepts in the management of Helicobacter pylori infection: the Maastricht III Consensus Report. Gut 56, 772-781.

Malfertheiner, P., Megraud, F., O’Morain, C., Gisbert, J., Kuipers, E., Axon, A., et al., 2016. Management of Helicobacter pylori infection-the maastricht V/Florence consensus report. Gut 61, 646-664. doi:http://dx.doi.org/10.1136/gutjnl-2016312288.

Mamont, P.S., Boehlen, P., Mccann, P.P., Bey, P., Schuber, F., Tardif, C., 1976. Alphamethyl ornithine, a potent competitive inhibitor of ornithine decarboxylase, blocks proliferation of rat hepatoma cells in culture. Proc. Natl. Acad. Sci. 73 1626-1630.

March, C.J., Mosley, B., Larsen, A., Cerretti, D.P., Braedt, G., Price, V., et al., 1985. Cloning, sequence and expression of two distinct human interleukincomplementary DNAs. Nature 315, 641.

Marcial, G., Sendker, J., Brandt, S., De Lampasona, M.P., Catalán, C.A., De Valdez, G.F., et al., 2014. Gastroprotection as an example Antiadhesion against Helicobacter pylori, anti-inflammatory and antioxidant activities of aqueous extracts from the aerial parts of Lippia integrifolia Hieron. J. Ethnopharmacol. 155, 1125-1133.

Márquez, N., Sancho, R., Macho, A., Calzado, M.A., Fiebich, B.L., Muñoz, E. 2004. Caffeic acid phenethyl ester inhibits T-cell activation by targeting both nuclear factor of activated T-cells and NF-кB transcription factors. J. Pharmacol. Exp. Ther 308, 993-1001.

Masadeh, M.M., Alkofahi, A.S., Alzoubi, K.H., Tumah, H.N., Bani-Hani, K., 2014. AntiHelicobactor pylori activity of some Jordanian medicinal plants. Pharm. Biol. 52, $566-569$.

Matsumoto, Y., Marusawa, H., Kinoshita, K., Endo, Y., Kou, T., Morisawa, T., et al., 2007. Helicobacter pylori infection triggers aberrant expression of activationinduced cytidine deaminase in gastric epithelium. Nat. Med. 13, 470-476.

Matsushima, M., Suzuki, T., Masui, A., Kasai, K., Kouchi, T., Takagi, A., et al., 2008. Growth inhibitory action of cranberry on Helicobacter pylori. J. Gastroenterol. Hepatol. 23, S175-S180.

Mazel, D., Pochet, S., Marliere, P. 1994 Genetic characterization of polypeptide deformylase, a distinctive enzyme of eubacterial translation. The EMBO J. 13, 914.

Mekori, Y.A., Metcalfe, D.D., 2000. Mast cells in innate immunity. Immunol. Rev.173, $131-140$.

Messing, J., Niehues, M., Shevtsova, A., Borén, T., Hensel, A., 2014. Antiadhesive properties of arabinogalactan protein from Ribes nigrum seeds against bacterial adhesion of Helicobacter pylori. Molecules 19, 3696-3717.

Michaluart, P., Masferrer, J.L., Carothers, A.M., Subbaramaiah, K., Zweifel, B.S., Koboldt, C., et al., 1999. Inhibitory effects of caffeic acid phenethyl ester on the activity and expression of cyclooxygenase- 2 in human oral epithelial cells and in a rat model of inflammation. Cancer Res. 59, 2347-2352. 
Min, D., Shin, M.H., 2009. NADPH oxidase-derived ROS mediates mast cell degranulation induced by secretory products secreted by Trichomonas vaginalis (133.5). J. Immunol. 182 (1), 133.5.

Miyamoto, T., Okimoto, T., Kuwano, M., 2014. Chemical composition of the essential oil of mastic gum and their antibacterial activity against drug-resistant Helicobacter pylori. Nat. Prod. Bioprospect. 4, 227-231.

Miyara, M., Gorochov, G., Ehrenstein, M., Musset, L., Sakaguchi, S., Amoura, Z., 2011. Human FoxP3+ regulatory T cells in systemic autoimmune diseases. Autoimmun. Rev. 10, 744-755.

Miyataka, H., Nishiki, M., Matsumoto, H., Fujimoto, T., Matsuka, M., Satoh, T., 1997. Evaluation of propolis. I. Evaluation of Brazilian and Chinese propolis by enzymatic and physico-chemical methods. Biol. Pharm. Bull. 20, 496-501.

Miyazawa, M., Utsunomiya, H., Inada, K.-I., Yamada, T., Okuno, Y., Tanaka, H., et al. 2006. Inhibition of Helicobacter pylori motility by (+) -Syringaresinol from unripe Japanese apricot. Biol. Pharm. Bull. 29, 172-173.

Mizuki, I., Shimoyama, T., Fukuda, S., Liu, Q., Nakaj, I.S., Munakata, A., 2000. Association of gastric epithelial apoptosis with the ability of Helicobacter pylori to induce a neutrophil oxidative burst. J. Med. Microbiol. 49, 521-524.

Molina-Infante, J., Perez-Gallardo, B., Fernandez-Bermejo, M., Hernandez-Alonso, M., Vinagre, G., Duenas, C., et al., 2010. Clinical trial: clarithromycin vs. levofloxacin in first-line triple and sequential regimens for Helicobacter pylori eradication, Alimentary. Pharmacol. Ther. 31, 1077-1084.

Møller, H., Heseltine, E., Vainio, H., 1995. Working group report on schistosomes, liver flukes and Helicobacter pylori. Meeting held at IARC, Lyon, 7-14 June 1994 Int. J. Cancer 60, 587-589.

Montemurro, P., Nishioka, H., Dundon, W.G., De Bernard, M., Del Giudice, G., Rappuoli, R., et al., 2002. The neutrophil-activating protein (HP-NAP) of Helicobacter pylori is a potent stimulant of mast cells. Eur. J. Immunol. 32, 671676.

Mori, N., Sato, H., Hayashibara, T., Senba, M., Geleziunas, R., Wada, A., et al., 2003. Helicobacter pylori induces matrix metalloproteinase- 9 through activation of nuclear factor $\kappa$ B. Gastroenterology 124, 983-992.

Murali, M.R., Naveen, S.V., Son, C.G., Balaji Raghavendran, H.R., 2014. Current knowledge on alleviating $H$. pylori infections through the use of some commonly known natural products: bench to bedside. Integr. Med. Res. 3 (3), 111-118.

Murata-Kamiya, N., Kurashima, Y., Teishikata, Y., Yamahashi, Y., Saito, Y., Higashi, H., et al., 2007. Helicobacter pylori CagA interacts with E-cadherin and deregulates the $\beta$-catenin signal that promotes intestinal transdifferentiation in gastric epithelial cells. Oncogene 26, 4617-4626.

Naito, Y., Yoshikawa, T., 2002. Molecular and cellular mechanisms involved in Helicobacter pylori-induced inflammation and oxidative stress 1, 2. Free Radic. Biol. Med. 33, 323-336.

Nakajima, S., Krishnan, B., Ota, H., Segura, A., Hattori, T., Graham, D.Y., et al., 1997. Mast cell involvement in gastritis with or without Helicobacter pylori infection. Gastroenterology 113, 746-754.

Natarajan, K., Singh, S., Burke, T.R., Grunberger, D., Aggarwal, B.B., 1996. Caffeic acid phenethyl ester is a potent and specific inhibitor of activation of nuclear transcription factor NF-kappa B. Proc. Natl. Acad. Sci. 93, 9090-9095.

Ndip, R.N., Tarkang, A.E.M., Mbullah, S.M., Luma, H.N., Malongue, A., Ndip, L.M., et al., 2007. In vitro anti-Helicobacter pylori activity of extracts of selected medicinal plants from North West Cameroon. J. Ethnopharmacol. 114, 452-457.

Ngan, L.T.M., Moon, J.-K., Shibamoto, T. Ahn, Y.-J., 2012. Growth-inhibiting, bactericidal, and urease inhibitory effects of Paeonia lactiflora root constituents and related compounds on antibiotic-susceptible and-resistant strains of Helicobacter pylori. J. Agric. Food Chem. 60, 9062-9073.

Njume, C., Jide, A.A., Ndip, R.N., 2011. Aqueous and organic solvent-extracts of selected South African medicinal plants possess antimicrobial activity against drug-resistant strains of Helicobacter pylori: inhibitory and bactericidal potential. Int. J. Mol. Sci. 12, 5652-5665.

Noach, L.A., Bosma, N.B., Jansen, J., Hoek, F.J., Van Deventer, S.J.H., Tytgat, G.N.J., 1994. Mucosal tumour necrosis factor-or, Interleukin-1/3, and Interleukin-8 production in patients with Helicobacter pylori infection. Scand. J. Gastroenterol. 29 (5), 425-429.

Nontakham, J., Charoenram, N., Upamai, W., Taweechotipatr, M., Suksamrarn, S., 2014. Anti-Helicobacter pylori xanthones of Garcinia fusca. Archives of Pharm Res. 37, 972-977.

Nostro, A., Cellini, L., Bartolomeo, S.D., Cannatelli, M., Campli, E.D., Procopio, F., et al., 2006. Effects of combining extracts (from propolis or Zingiber officinale) with clarithromycin on Helicobacter pylori. Phytother. Res. 20, 187-190.

O'Gara, E.A., Maslin, D.J., Nevill, A.M., Hill, D.J., 2008. The effect of simulated gastric environments on the anti-Helicobacter activity of garlic oil. J. Appl. Microbiol. 104, 1324-1331.

Odenbreit, S., Püls, J., Sedlmaier, B., Gerland, E., Fischer, W., Haas, R., 2000. Translocation of Helicobacter pylori CagA into gastric epithelial cells by type IV secretion. Science 287, 1497-1500.

Oršolić, N., Bašić, I., 2003. Immunomodulation by water-soluble derivative of propolis: a factor of antitumor reactivity. J. Ethnopharmacol. 84, 265-273.

Osman, S.M., Gamil, L., Ramadan, M.A., 2015. Bioactivity guided study of antiHelicobacter activity of Ruta graveolens. Int. J. Appl. Res. Nat. Prod. 8, 1-5.

Palacios-Espinosa, J.F. Arroyo-García, O., García-Valencia, G., Linares, E., Bye, R. Romero, I., 2014. Evidence of the anti-Helicobacter pylori, gastroprotective and anti-inflammatory activities of Cuphea aequipetala infusion. J. Ethnopharmacol. 151, 990-998.

Pan-In, P., Tachapruetinun, A., Chaichanawongsaroj, N., Banlunara, W., Suksamrarn, S., Wanichwecharungruang, S., 2014. Combating Helicobacter pylori infections with mucoadhesive nanoparticles loaded with Garcinia mangostana extract. Nanomedicine 9, 457-468.

Paoluzi, O.A., Visconti, E., Andrei, F., Tosti, C., Lionetti, R., Grasso, E., et al., 2010. Ten and eight-day sequential therapy in comparison to standard triple therapy for eradicating Helicobacter pylori infection: a randomized controlled study on efficacy and tolerability. J. Clin. Gastroenterol. 44, 261-266.

Paraschos, S., Magiatis, P., Mitakou, S., Petraki, K., Kalliaropoulos, A., Maragkoudakis, P., et al., 2007. In vitro and in vivo activities of Chios mastic gum extracts and constituents against Helicobacter pylori. Antimicrob. Agents Chemother. 51, 551-559.

Park, J.M., Park, S.H., Hong, K.S., Han, Y.M., Jang, S.H., Kim, E.H., et al., 2014. Special liquorice extracts containing lowered glycyrrhizin and enhanced licochalcone A prevented Helicobacter pylori-initiated: salt diet-promoted gastric tumorigenesis. Helicobacter 19, 221-236.

Park, W.S., Kim, H., Lee, W., Baik, S., Lee, M., 2015. Anti-Helicobacter pylori compounds from Maackia amurensis. Nat. Prod. Sci. 21, 49-53.

Pascual, C., Gonzalez, R., Torricella, R., 1994. Scavenging action of propolis extract against oxygen radicals. J. Ethnopharmacol. 41, 9-13.

Pastene, E., Speisky, H.N., Troncoso, M., Alarco'n, J., Figueroa, G., 2009a. In vitro inhibitory effect of apple peel extract on the growth of Helicobacter pylori and respiratory burst induced on human neutrophils. J. Agric. Food Chem. 57, 77437749.

Pastene, E., Troncoso, M., Figueroa, G., Alarco'n, J., Speisky, H.N., 2009b. Association between polymerization degree of apple peel polyphenols and inhibition of Helicobacter pylori urease. J. Agric. Food Chem. 57, 416-424.

Paulino, N., Abreu, S.R.L., Uto, Y., Koyama, D., Nagasawa, H., Hori, H., et al., 2008. Anti inflammatory effects of a bioavailable compound, Artepillin C, in Brazilian propolis. Eur. J. Pharmacol. 587, 296-301.

Peek Jr., R.M., Miller, G.G., Tham, K.T., Perez-Perez, G.I., Zhao, X., Atherton, J.C., et al., 1995. Heightened inflammatory response and cytokine expression in vivo to cagA+ Helicobacter pylori strains. Lab. Invest. 73, 760-770.

Peek, R.M., Blaser, M.J., 2002. Helicobacter pylori and gastrointestinal tract adenocarcinomas. Nat. Rev. Cancer 2, 28-37.

Penas, E.M., Hinz, K., Röser, K., Copie-Bergman, C., Wlodarska, I., Marynen, P., et al., 2003. Translocations $\mathrm{t}(11 ; 18)(\mathrm{q} 21 ; \mathrm{q} 21)$ and $\mathrm{t}(14 ; 18)(\mathrm{q} 32 ; \mathrm{q} 21)$ are the main chromosomal abnormalities involving MLT/MALT1 in MALT lymphomas. Leukemia 17, 2225-2229.

Perna, F., Zullo, A., Ricci, C., Hassan, C., Morini, S., Vaira, D., 2007. Levofloxacin-based triple therapy for Helicobacter pylori re-treatment: role of bacterial resistance. Dig. Liver Dis. 39, 1001-1005.

Polenghi, A., Bossi, F., Fischetti, F., Durigutto, P., Cabrelle, A., Tamassia, N., et al., 2007 The neutrophil-activating protein of Helicobacter pylori crosses endothelia to promote neutrophil adhesion in vivo. J. Immunol. 178, 1312-1320.

Pomorski, T., Meyer, T.F., Naumann, M., 2001. Helicobacter pylori-induced prostaglandin E2 synthesis involves activation of cytosolic phospholipase A2 in epithelial cells. J. Biol. Chem. 276, 804-810.

Quílez, A., Berenguer, B., Gilardoni, G., Souccar, C., De Mendonça, S., Oliveira, L., et al , 2010. Anti-secretory, anti-inflammatory and anti-Helicobacter pylori activities of several fractions isolated from Piper carpunya Ruiz and Pav. J. Ethnopharmacol. 128, 583-589.

Ramakrishna, Y.G., Savithri, K., Kist, M., Devaraj, S.N., 2015. Aegle marmelos fruit extract attenuates Helicobacter pylori Lipopolysaccharide induced oxidative stress in Sprague Dawley rats. BMC Complement. Altern. Med. 15, 1.

Rao, C.V., Desai, D., Kaul, B., Amin, S., Reddy, B.S., 1992. Effect of caffeic acid esters on carcinogen-induced mutagenicity and human colon adenocarcinoma cell growth. Chem. Biol. Interact. 84, 277-290.

Rao, Y.K., Lien, H.-M., Lin, Y.-H., Hsu, Y.-M., Yeh, C.-T., Chen, C.-C., et al., 2012 Antibacterial activities of Anisomeles indica constituents and their inhibition effect on Helicobacter pylori-induced inflammation in human gastric epithelial cells. Food Chem. 132, 780-787.

Rice-Evans, C.A., Miller, N.J., Paganga, G., 1996. Structure-antioxidant activity relationships of flavonoids and phenolic acids. Free Radic. Biol. Med. 20, 933 956.

Roe, I., Nam, S., Kim, J., Shin, J., Bang, W., Yang, M., 2002. Association of the myeloperoxidase $-463 \mathrm{G}$ polymorphism with development of atrophy in Helicobacter pylori-infected gastritis. Am. J. Gastroenterol. 97, 1629-1634.

Ruskone-Fourmestraux, A., Lavergne, A., Aegerter, P., Megraud, F., Palazzo, L., De Mascarel, A., et al., 2001. Predictive factors for regression of gastric MALT lymphoma after anti-Helicobacter pylori treatment. Gut 48, 297-303.

Russo, A., Longo, R., Vanella, A., 2002. Antioxidant activity of propolis: role of caffeic acid phenethyl ester and galangin. Fitoterapia 73, S21-S29.

Sackmann, M., Morgner, A., Rudolph, B., Neubauer, A., Thiede, C., Schulz, H., et al. 1997. Regression of gastric MALT lymphoma after eradication of Helicobacter pylori is predicted by endosonographic staging: MALT Lymphoma Study Group. Gastroenterology 113, 1087-1090.

Saito, Y., Suzuki, H., Tsugawa, H., Imaeda, H., Matsuzaki, J., Hirata, K., et al., 2012. Overexpression of miR-142-5p and miR-155 in gastric mucosa-associated lymphoid tissue (MALT) lymphoma resistant to Helicobacter pylori eradication. PLoS One. 7, e47396.

Sarkar, D., Ankolekar, C., Pinto, M., Shetty, K., 2015. Dietary functional benefits of Bartlett and Starkrimson pears for potential management of hyperglycemia: hypertension and ulcer bacteria Helicobacter pylori while supporting beneficial probiotic bacterial response. Food Res. Int. 69, 80-90.

Satin, B., Del Giudice, G., Della Bianca, V., Dusi, S., Laudanna, C., Tonello, F., et al., 2000. The neutrophil-activating protein (HP-NAP) of Helicobacter pylori is a protective antigen and a major virulence factor. J. Exp. Med. 191, 1467-1476. 
Schmidt, U., Abramova, A., Boucheron, N., Eckelhart, E., Schebesta, A., Bilic, I., et al. 2009. The protein tyrosine kinase Tec regulates mast cell function. Eur. J Immunol. 39, 3228-3238.

Schmitt, W., Haas, R., 1994. Genetic analysis of the Helicobacter pylori vacuolating cytotoxin: structural similarities with the IgA protease type of exported protein. Mol. Microbiol. 12, 307-319.

Sharma, S.A., Tummuru, M.K., Blaser, M.J., Kerr, L.D., 1998. Activation of IL-8 gene expression by Helicobacter pylori is regulated by transcription factor nuclear factor-КB in gastric epithelial cells. J. Immunol. 160, 2401-2407.

Sidahmed, H.M.A., Hashim, N.M., Abdulla, M.A., Ali, H.M., Mohan, S., Abdelwahab, S I., et al., 2015. Antisecretory, gastroprotective, antioxidant and anti-Helicobacte pylori activity of zerumbone from Zingiber Zerumbet (L.) Smith. PLoS One 10, e0121060.

Sidahmed, H.M.A., Hashim, N.M., Mohan, S., Abdelwahab, S.I., Taha, M.M.E Dehghan, F., et al., 2016. Evidence of the gastroprotective and anti-Helicobacter pylori activities of $\beta$-mangostin isolated from Cratoxylum arborescens (vahl) blume. Drug Design Dev. Ther. 10, 297.

Siddaraju, M., Dharmesh, S.M., 2007. Inhibition of gastric $\mathrm{H}+, \mathrm{K}+-\mathrm{ATP} a \mathrm{se}$ and Helicobacter pylori growth by phenolic antioxidants of Curcuma amada. J. Agric Food Chem. 55, 7377-7386.

Sidebotham, R., Batten, J., Karim, Q., Spencer, J., Baron, J., 1991. Breakdown of gastric mucus in presence of Helicobacter pylori. J. Clin. Pathol, 44, 52-57.

Silva, L.P., De Angelis, C.D., Bonamin, F., Kushima, H., Mininel, F.J., Dos Santos, L.C., et al., 2015. Terminalia catappa L.: a medicinal plant from the Caribbean pharmacopeia with anti-Helicobacter pylori and antiulcer action in experimental rodent models. J. Ethnopharmacol. 159, 285-295.

Simões, L., Gregório, L., Da Silva Filho, A., De Souza, M., Azzolini, A., Bastos, J., et al. 2004. Effect of Brazilian green propolis on the production of reactive oxygen species by stimulated neutrophils. J. Ethnopharmacol. 94, 59-65.

Skiba, M., Szliszka, E., Kunicka, M., Krol, W., 2011. Effect of ethanol extract of propolis (EEP) on interleukin 8 release by human gastric adenocarcinoma cells (AGS) infected with Helicobacter pylori. Central-Eur. J. Immunol. 36, 65-69.

Smith, S., Boyle, B., Brennan, D., Buckley, M., Crotty, P., Doyle, M., et al., 2017. The Irish Helicobacter pylori working group consensus for the diagnosis and treatment of H. pylori infection in adult patients in Ireland. Eur. J. Gastroenterol. Hepatol. 29, $552-559$.

Smoot, D.T., Elliott, T.B., Verspaget, H.W., Jones, D., Allen, C.R., Vernon, K.G., et al., 2000. Influence of Helicobacter pylori on reactive oxygen-induced gastric epithelial cell injury. Carcinogenesis 21, 2091-2095.

Song, Y.S., Park, E.-H., Hur, G.M., Ryu, Y.S., Kim, Y.M., Jin, C., 2002. Ethanol extract of propolis inhibits nitric oxide synthase gene expression and enzyme activity. J. Ethnopharmacol. 80, 155-161.

Srikanta, B.M., Nayaka, M.A.H., Dharmesh, S.M., 2011. Inhibition of Helicobacter pylori growth and its cytotoxicity by 2-hydroxy 4-methoxy benzaldehyde of Decalepis hamiltonii (Wight \& Arn): a new functional attribute. Biochemie 93, $678-688$.

Stein, M., Bagnoli, F., Halenbeck, R., Rappuoli, R., Fantl, W.J., Covacci, A., 2002. c-Src/ Lyn kinases activate Helicobacter pylori CagA through tyrosine phosphorylation of the EPIYA motifs. Mol. Microbiol. 43, 971-980.

Strehl, E., Volpert, R., Elstner, E.F., 1994. Biochemical activities of propolis-extracts III. Inhibition of dihydrofolate reductase. Zeitschrift für Naturforschung c. 49, 39-43.

Suerbaum, S., Smith, J.M., Bapumia, K., Morelli, G., Smith, N.H., Kunstmann, E., et al. 1998. Free recombination within Helicobacter pylori. Proc. Natl. Acad. Sci. 95, $12619-12624$.

Supajatura, V., Ushio, H., Wada, A., Yahiro, K., Okumura, K., Ogawa, H., et al., 2002 Cutting edge VacA, a vacuolating cytotoxin of Helicobacter pylori, directly ctivates mast cells for migration and production of proinflammatory cytokines. J. Immunol. 168, 2603-2607.

Suzuki, M., Miura, S., Suematsu, M., Fukumura, D., Kurose, I., Suzuki, H., et al., 1992 Helicobacter pylori-associated ammonia production enhances neutrophildependent gastric mucosal cell injury. Am. J. Physiol. Gastrointest. Liver Physiol. 263, G719-G725.

Tatsuguchi, A., Sakamoto, C., Wada, K., Akamatsu, T., Tsukui, T., Miyake, K., et al., 2000. Localisation of cyclooxygenase 1 and cyclooxygenase 2 in Helicobacter pylori related gastritis and gastric ulcer tissues in humans. Gut 46, 782-789.

Tharmalingam, N., Park, M., Lee, M.H., Woo, H.J., Kim, H.W., Yang, J.Y., et al., 2016. Piperine treatment suppresses Helicobacter pylori toxin entry in to gastric epithelium and minimizes $\beta$-catenin mediated oncogenesis and IL-8 secretion in vitro. Am. J. Transl. Res. 8, 885

Thiery, J.P., 2002. Epithelial-mesenchymal transitions in tumour progression. Nat. Rev Cancer 2, 442-454.

Thompson Coon, J., Ernst, E., 2002. Herbal medicinal products for non-ulcer dyspepsia. Aliment. Pharmacol. Ther. 16, 1689-1699.

Thung, I., Aramin, H., Vavinskaya, V., Gupta, S., Park, J., Crowe, S., et al., 2016. The global emergence of Helicobacter pylori antibiotic resistance. Aliment. Pharmacol. Ther. 43, 514-533.

Tomb, J.-F., White, O., Kerlavage, A.R., Clayton, R.A., Sutton, G.G., Fleischmann, R.D. et al., 1997. The complete genome sequence of the gastric pathogen Helicobacter pylori. Nature 388, 539-547.

Valente, M.J., Baltazar, A.F., Henrique, R., Estevinho, L., Carvalho, M., 2011. Biological activities of Portuguese propolis: protection against free radical-induced erythrocyte damage and inhibition of human renal cancer cell growth in vitro. Food Chem. Toxicol. 49, 86-92.

Vega, A., Wendel, G., Maria, A., Pelzer, L., 2009. Antimicrobial activity of Artemisia douglasiana and dehydroleucodine against Helicobacter pylori. J. Ethnopharmacol. 124, 653-655.
Viala, J., Chaput, C., Boneca, I.G., Cardona, A., Girardin, S.E., Moran, A.P., et al., 2004 Nod1 responds to peptidoglycan delivered by the Helicobacter pylori cag pathogenicity island. Nat. Immunol. 5, 1166-1174.

Vítor, J.M., Vale, F.F., 2011. Alternative therapies for Helicobacter pylori: probiotics and phytomedicine. FEMS Immunol. Med. Microbiol. 63, 153-164.

Voravuthikunchai, S.P., Mitchell, H., 2008. Inhibitory and killing activities of medicinal plants against multiple antibiotic-resistant Helicobacter pylori. J. Health Sci. 54, 81-88.

Voravuthikunchai, S.P., Limsuwan, S., Mitchell, H., 2006. Effects of Punica granatum pericarps and Quercus infectoria nutgalls on cell surface hydrophobicity and cell survival of Helicobacter pylori. J. Health Sci. 52, 154-159.

Walker, P., Crane, E., 1987. Constituents of propolis. Apidologie 18, 327-334.

Wang, Y.-C., Lin, Y.-H., 2012. Anti-gastric adenocarcinoma activity of 2-methoxy-1, 4-naphthoquinone, an anti-Helicobacter pylori compound from Impatiens balsamina L. Fitoterapia 83, 1336-1344.

Wen, S., Felley, C.P., Bouzourene, H., Reimers, M., Michetti, P., Pan-Hammarström, Q., 2004. Inflammatory gene profiles in gastric mucosa during Helicobacter pylori infection in humans. J. Immunol. 172, 2595-2606.

Wessler, S., 2016. Emerging novel virulence factors of Helicobacter pylori. In: Backert, S., Yamaoka, Y. (Eds.), Helicobacter Pylori Research: from Bench to Bedside. Springer, Tokyo, pp. 165-188.

Westblom, T.U., Czinn, S.J., Nedrud, J.G. (Eds.), 1999. Gastroduodenal Disease and Helicobacter Pylori: Pathophysiology, Diagnosis and Treatment. Springer, Berlin.

Willhite, D.C., Cover, T.L., Blanke, S.R., 2003. Cellular vacuolation and mitochondrial cytochrome c release are independent outcomes of Helicobacter pylori vacuolating cytotoxin activity that are each dependent on membrane channel formation. J. Biol. Chem. 278, 48204-48209.

Wroblewski, L.E., Noble, P.-J., Pagliocca, A., Pritchard, D.M., Hart, C.A., Campbell, F., et al., 2003. Stimulation of MMP-7 (matrilysin) by Helicobacter pylori in human gastric epithelial cells: role in epithelial cell migration. J. Cell Sci. 116, 30173026.

Wu, Y.-Y., Tsai, H.-F, Lin, W.-C., Hsu, P.-I., Shun, C.-T., Wu, M.-S, et al., 2007. Upregulation of CCL20 and recruitment of CCR6+ gastric infiltrating lymphocytes in Helicobacter pylori gastritis. Infect. Immun. 75, 4357-4363.

Xie, J., Lin, Z., Xian, Y., Kong, S., Lai, Z., Ip, S., et al., 2016. (-) -Patchouli alcohol protects against Helicobacter pylori urease-induced apoptosis, oxidative stress and inflammatory response in human gastric epithelial cells. Int. Immunopharmacol. 35, 43-52.

Xu, H., Chaturvedi, R., Cheng, Y., Bussiere, F.I., Asim, M., Yao, M.D., et al., 2004 Spermine oxidation induced by Helicobacter pylori results in apoptosis and DNA damage implications for gastric carcinogenesis. Cancer Res. 64, 8521-8525.

Yakoob, J., Jafri, W., Mehmood, M.H., Abbas, Z., Tariq, K., 2015. Immunomodulatory effects of Psyllium extract on Helicobacter pylori interaction with gastric epithelial cells. J. Evid.- Based Complement. Altern. Med. 21 (4), NP18-24.

Yamada, T., Wei, M., Toyoda, T., Yamano, S., Wanibuchi, H., 2014. Inhibitory effect of raphanobrassica on Helicobacter pylori-induced gastritis in Mongolian gerbils. Food Chem. Toxicol. 70, 107-113.

Yamaoka, Y., Kita, M., Kodama, T., Sawai, N., Tanahashi, T., Kashima, K., et al., 1998. Chemokines in the gastric mucosa in Helicobacter pylori infection. Gut 42, 609617.

Yamaoka, Y., Kwon, D.H., Graham, D.Y., 2000. A Mr 34,000 proinflammatory outer membrane protein (oipA) of Helicobacter pylori. Proc. Natl. Acad. Sci. 97, 75337538.

Yan, F., Cao, H., Chaturvedi, R., Krishna, U., Hobbs, S.S., Dempsey, P.J., et al., 2009. Epidermal growth factor receptor activation protects gastric epithelial cells from Helicobacter pylori-induced apoptosis. Gastroenterology 136, 1297-1307 (3e).

Yanagawa, Y., Yamamoto, Y., Hara, Y., Shimamura, T., 2003. A combination effect of epigallocatechin gallate, a major compound of green tea catechins, with antibiotics on Helicobacter pylori growth in vitro. Curr. Microbiol. 47, 0244-0249.

Yanaka, A., Fahey, J.W., Fukumoto, A., Nakayama, M., Inoue, S., Zhang, S., et al., 2009. Dietary sulforaphane-rich broccoli sprouts reduce colonization and attenuate gastritis in Helicobacter pylori-infected mice and humans. Cancer Prevent. Res. 2, 353-360.

Yang, J.-C., Lu, C.-W., Lin, C.-J., 2014. Treatment of Helicobacter pylori infection current status and future concepts. World J. Gastroenterol. 20, 5283-5293.

Yoshikawa, K., Okazaki, I.-M., Eto, T., Kinoshita, K., Muramatsu, M., Nagaoka, H., et al. 2002. AID enzyme-induced hypermutation in an actively transcribed gene in fibroblasts. Science 296, 2033-2036.

Yoshimura, T., Matsushima, K., Oppenheim, J.J., Leonard, E.J., 1987. Neutrophil chemotactic factor produced by lipopolysaccharide (LPS)-stimulated human blood mononuclear leukocytes: partial characterization and separation from interleukin 1 (IL 1). J. Immunol. 139, 788-793.

Zaidi, S.F.H., Yamamoto, T., Refaat, A., Ahmed, K., Sakurai, H., Saiki, I., et al., 2009a. Modulation of activation-induced cytidine deaminase by curcumin in Helicobacter pylori-infected gastric epithelial cells. Helicobacter 14, 588-595.

Zaidi, S.F.H., Yoshida, I., Butt, F., Yusuf, M.A., Usmanghani, K., Kadowaki, M., et al. 2009b. Potent bactericidal constituents from Mallotus philippinensis against clarithromycin and metronidazole resistant strains of Japanese and Pakistani Helicobacter pylori. Biol. Pharm. Bull. 32, 631-636.

Zhang, X.-Q., Gu, H.-M., Li, X.-Z., Xu, Z.-N., Chen, Y.-S., Li, Y. 2013, Anti-Helicobacter pylori compounds from the ethanol extracts of Geranium wilfordii. J. Ethnopharmacol. 147, 204-207.

Zhou, Y., Taylor, B., Smith, T.J., Liu, Z.P., Clench, M., Davies, N.W., et al., 2009. A novel compound from celery seed with a bactericidal effect against Helicobacter pylori. J. Pharm. Pharmacol. 61, 1067-1077. 